\title{
Engram formation in psychiatric disorders
}

\author{
Peter J. Gebicke-Haerter ${ }^{1,2 *}$ \\ ${ }^{1}$ Medical Faculty Mannheim, Central Institute of Mental Health, Institute of Psychopharmacology, Heidelberg University, Mannheim, Germany \\ 2 Progrs. de Farmacología y Inmunología, Facultad de Medicina, Universidad de Chile, Santiago, Chile
}

\section{Edited by:}

Hiroaki Kitano, The Systems Biology Institute, Japan

Reviewed by:

Steven G. Gray, St. James

Hospital/Trinity College Dublin,

Ireland

Bibhash Mukhopadhyay, Johnson \&

Johnson, USA

*Correspondence:

Peter J. Gebicke-Haerter, Medical

Faculty Mannheim, Central Institute

of Mental Health, Institute of

Psychopharmacology, Heidelberg

University, J5, 68159 Mannheim,

Germany

e-mail:peter.gebicke@

zi-mannheim.de;

pgebicke-haerter@med.uchile.cl
Environmental factors substantially influence beginning and progression of mental illness, reinforcing or reducing the consequences of genetic vulnerability. Often initiated by early traumatic events, "engrams" or memories are formed that may give rise to a slow and subtle progression of psychiatric disorders. The large delay between beginning and time of onset (diagnosis) may be explained by efficient compensatory mechanisms observed in brain metabolism that use optional pathways in highly redundant molecular interactions. To this end, research has to deal with mechanisms of learning and long-term memory formation, which involves (a) epigenetic changes, (b) altered neuronal activities, and (c) changes in neuron-glia communication. On the epigenetic level, apparently DNA-methylations are more stable than histone modifications, although both closely interact. Neuronal activities basically deliver digital information, which clearly can serve as basis for memory formation (LTP). However, research in this respect has long time neglected the importance of glia. They are more actively involved in the control of neuronal activities than thought before. They can both reinforce and inhibit neuronal activities by transducing neuronal information from frequency-encoded to amplitude and frequency-modulated calcium wave patterns spreading in the glial syncytium by use of gap junctions. In this way, they serve integrative functions. In conclusion, we are dealing with two concepts of encoding information that mutually control each other and synergize: a digital (neuronal) and a wave-like (glial) computing, forming neuron-glia functional units with inbuilt feedback loops to maintain balance of excitation and inhibition. To better understand mental illness, we have to gain more insight into the dynamics of adverse environmental impact on those cellular and molecular systems. This report summarizes existing knowledge and draws some outline about further research in molecular psychiatry.

Keywords: neuronal networks, computational simulation, synaptic engram, cross-frequency coupling, gap junctions, post-translational modifications, epigenetics, schizophrenia

\section{INTRODUCTION}

A widely-accepted hypothesis of the origin of schizophrenia posits that perinatal insults play major roles as triggering events in the development of the disorder. One of these insults is reduced oxygen supply, a condition not uncommon at delivery and supposedly affecting the brain more than other organs. Evidently, this cannot be the whole story. Mental disorders like any other disease develop stepwise or, described in a more abstract way, as sequences of yes/no decisions or "bifurcations," a term used in mathematics (chaos theory) for a long time. Along these lines, one could understand the development of an organism or the brain as the formation of a tree-like structure, unique and specific for each single individual, devolving and maintaining characteristic dynamics during the whole life span. That means, that the course of single events is not linear (50\% yes/ 50\% no decisions for each bifurcation are only a statistical probability, but do not reflect biological reality). Some may reinforce a certain direction, others may compensate for events drifting into adverse directions. Compensatory mechanisms inherent to all biological systems play a pivotal role, anyway. Dependent on the strength of adverse impacts and their specific accumulation over time, a disease may become evident and diagnosable within a short period of time or, as observed in most diseases of the brain, only after a long time of concealed progression. Consequently, this implies a sustained process of disease development divided in two parts, the "unnoticed" and the "recognizable" part. Clearly, both parts are relative, depending on the available technological tools to identify and confirm signs of a mental illness.

Obviously, this not only applies for the development of psychiatric disorders but also for the status of health, mental skills like intelligence and geniality. In order to understand these processes in more detail, we have to elaborate on the way how learning and long-term memory is produced and stored in the Central Nervous System (CNS), assuming that induction and progression of those disorders are based on the same mechanisms. The long-term memory process can be generally divided into four distinct stages: learning, consolidation, storage and retrieval. The storage of information is a delicate balancing act. The nervous system has to decide, which of the incoming new information is worth to be selected for consolidation and long-term storage, and which should be discarded, to avoid overload of storage capacity. Thereafter, stored informations have to be sufficiently stable, but have to be available for rapid retrieval, as well. 
Several studies identified the hippocampus as an important site for consolidating labile short-term memories into more stable long-term memories. After hippocampal-dependent consolidation, these memories are thought to be transferred to and stored in the cortex (Wiltgen et al., 2004). This somewhat delayed consolidation process is believed to reflect the systems-level of memory consolidation, encompassing gradual reorganization of additional brain circuits and distribution of short-term memory to more remote cortical areas for permanent storage. For further consolidation, long-term memories in cortical areas seem to require so-called reactivation of the hippocampus that acts as a coincidence-regenerator (Squire et al., 2004). Hence, the hippocampus initially works with the neocortex to consolidate memory. Subsequently, changes in the neocortex over time become more essential for storing the information by restructuring connectivities among more distant cortical areas (Squire, 2009). This interaction is supposed to result in gradual strengthening of the cortical-cortical connectivity for permanent storage (Wittenberg and Tsien, 2002). Once those cortical connections become strongly consolidated, long-term memories can remain stable even in the absence of the hippocampus. In the literature those cortically stored long-term memories are often referred as remote memories (Wang et al., 2006).

Apparently any input, any contact with the environment impacts on the abovementioned yes/no decisions forming "engrams," which are theoretical constructs of the most basic units of memory. The term was used first by Semon (1921), describing it as "the enduring though primarily latent modification in the irritable substance produced by stimulus." In an extension of this view, the accumulation or synergistic combination of engrams may result in reinforced disease development or bolstered mental health, which entails the notion that any of these complex outcomes can only result from the interplay of many "memory traces." This leads us to issues of the physical substrates of memory formation and its stabilization over long time-supposedly until the end of life of a human being.

\section{SEARCH FOR PHYSICAL SUBSTRATES OF ENGRAMS NEURONAL NETWORKS AND COMPUTATIONAL NEUROSCIENCE}

Already over 40 years ago, specific cells (neurons) of the prefrontal cortex were identified as putative "memory cells" by their sustained activities over extended periods of time upon a triggering stimulus (Fuster and Alexander, 1971). This stimulated the search for neuronal ensembles or sites of the brain encoding memory (Sakaguchi and Hayashi, 2012). The brain region most thoroughly studied in this respect is the hippocampus. At least short-term memory appears to be encoded by cells of this region and may be gradually redistributed to other sites in the brain and stored as long-term memory. Whether there is really a strict regional separation between different types of memory and whether long-term memory is identical to the information stored as short-term memory is still a matter of an ongoing debate (Sutherland and Lehmann, 2011). Another issue worth mentioning in this context is the temporal aspect, i.e., that reexperiencing exactly the same event some time later does not necessarily activate the same neurons and therefore may not result in an identical memory trace (Vazdarjanova and Guzowski, 2004).
The high likelihood of these subtle variations stems from the marked combinatorial power that even resides in one given hippocampal granule cell with approximately 40,000 inputs. From those, roughly 400 are needed to trigger an action potential (McNaughton et al., 1981). A selection of any 400 combinations of inputs from the total of 40,000 results in a very large number $\left(1.21 \times 10^{96}\right)$ of combinations. Facing this enormous combinatorial variability available to any neuron in the hippocampus, it appears logical that even identical signals arriving from the environment, but at different times, trigger distinct selections of input combinations in different single neurons, and eventually produce accumulating, distinct patches of long-lasting memory. Conversely, it may be assumed, that retrieval of a particular memory at different times does not recruit the same group of neurons. In consequence, there is a number of similar neuronal networks encoding memory traces of the same event received at different times resulting in the development of relational networks (Eichenbaum, 2004). Opposing this concept, it has been reported some time ago, that the same ensemble of neurons in the hippocampus of rats is activated upon the same stimulus displayed a second time $30 \mathrm{~min}$ later (Guzowski et al., 1999). The Arc catFISH method used in this study for showing neuronal activation, however, does not necessarily prove that the labeled neurons encode the memory.

Along these lines, but apparently biased by the huge surge of computer technologies, the search for the physical basis of engrams, or how learning and memory are encoded, concentrated on neuronal ensembles or networks in analogy to integrated electrical circuits. In this respect, computational neurosciences have advanced considerably our understanding of the functioning and learning capacities of neuronal networks using mathematical tools, such as machine-learning algorithms (Hinton et al., 2006), or performing mathematical simulations with the goal to establish systems of artificial intelligence. Because they are dealing with networks in the sense of electronic circuits, they are essentially composed of "neurons" and their electric activities, albeit with modifications added upon increasing knowledge from biology. An attractive feature of neuronal circuitries appears to be their oscillatory behavior that may be useful to encode information derived from spatially nonhomogeneous and time-independent inputs into spatio-temporal codes. Hence, improvements of performance and robustness of the systems were achieved by coupling oscillators (two or more neuronal networks, Figure 1) and synchronize their frequencies (Orosz et al., 2009). Optionally, self-sustained feedback mechanisms resembling molecular oscillators, that are triggered by short-term memory, have been discussed along with memory consolidation (Bailey et al., 2004).

In this context, it was believed very early on, that a complete understanding of the wiring systems of neurons would enable us to obtain a detailed view into neuronal patterns of activity and resultant higher-level cognitive processes (Perkel, 1988). This "connectionism," assuming that neuronal networks are comparable to logical circuit elements that follow simple threshold rules, was the most convenient approach to apply physical sciences in brain research. More recent efforts to obtain a complete "connectome" of the mammalian nervous system renewed the interest in "connectionism" (Lichtman et al., 2008). However, no 


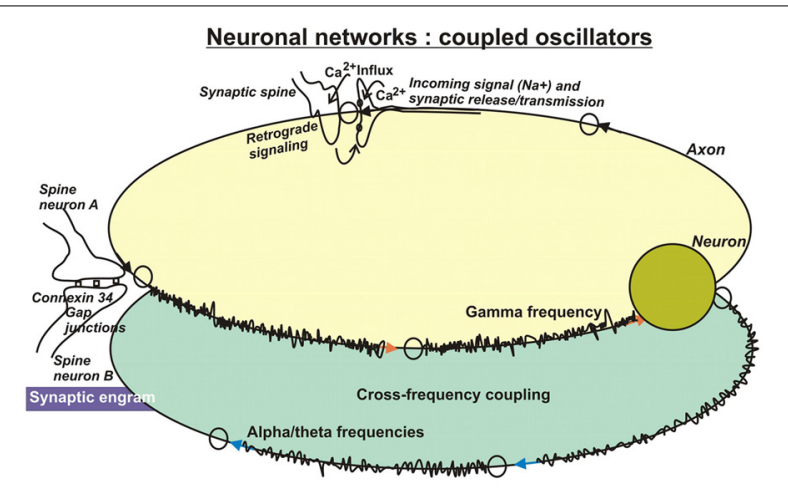

Engram formation by self-induction and maintenance of electric activities

FIGURE 1 | In search for substrates of engrams. Artificial neuronal networks have been studied intensively by computational tools, because they are reminiscent of integrated circuits used in computer technology.

Basically, the biological neuronal networks encode incoming information in digital ways, because their firing depends on critical thresholds that control yes/no responses. Encoding may be performed by the frequencies or by the amplitudes of firing, and may be modulated by cross-frequency coupling of two or more interacting networks. These circuits are characterized by self-induction and maintenance of electric activities. Therefore, the computational approach entails storage and retrieval of information on the electro (-physiological) level using feedforward and feedback loops. By and large, these models have been modified by taking into account specific biological features, such as time-delay functions as observed at neurotransmission at synapses, and weighted inputs owing to different synaptic strengths, just to mention a few improvements (for more, see text). The so-called electrical synapses connected by gap junctions serve lateral spreading of information in dendritic trees, and gave rise to the notion of a "synaptic engram." This special information processing entailed an additional challenge in models of computational neuroscience.

neuronal network is hard-wired. For this reason, these promising efforts had to be improved by taking into account some additional important and typical features of biological neuronal networks: their functioning in highly nonlinear, dynamic ways (Ramirez et al., 2004) with complex and reciprocal excitation-inhibition and bursting activities (Koch et al., 2011). Additionally, detailed aspects of (synaptic) plasticity and resultant changes of activity patterns are hard to be reconciled with concepts of connectionism. Therefore, by and large, algorithms have been developed that included one or the other of those additional features.

For example, the introduction of a time-delay function (Zou et al., 2012), which is owed to the intrinsic properties of synaptic neurotransmission, appeared to improve the memory storage capacities of neural networks without substantially increasing their size. It turned out, that the time-lag in conjunction with the firing process at the synapse, combined with inhibitory feedback and with the absolute refractory period, features that were already contained in the well-known Hodgkin-Huxley model (Foss et al., 1996), could indeed result in basic types of oscillations, as mentioned above. To further reconcile the fast dynamics of neuronal activities with the relatively slow dynamics of synaptic weights (more or less frequent use of a synapse), the previously developed Adaptive Resonance Theory (ART) (Carpenter and Grossberg, 1987) helped to reach some state of machine learning and to increase the capacity for memory storage and retrieval in a network of two layers of neurons (or neuron populations).

A further aspect, conflicting with engram formation on computational grounds, is the peculiarity of neurons to show rapid leakage of currents out of their membranes, which makes them inherently "forgetful." As a remedy, this leakage of currents was compensated for by insertion of memory cells in circuits containing positive-feedback loops. These cells are made to replace leaked currents exactly at the time when they are lost. Unfortunately, positive-feedback loops have the tendency to run out of control when they are not strictly balanced. Therefore, optional mechanisms with negative-derivative feedback were studied to evaluate their effects on generating sustained activity and temporal integration. Indeed, as published recently (Lim and Goldman, 2013), mechanisms based on negative-derivative feedback control maintain activity (memory) for long durations in a neural network after the stimulus has been removed, and may even serve as temporal integrators of their inputs.

Another conflicting aspect is synaptic plasticity, a process progressing throughout life, and characterized by axonal sprouting and formation of new axo-dendritic contacts (neuropoiesis). These new synaptic sprouts that have been observed along dendritic trees of layer $\mathrm{V}$ pyramidal cells, are formed in response to "experience" or "environmental cues" and are stimulated by electrophysiological events, like long term potentiation (LTP) in the proximal dendritic domains. Especially, the distinctions and the interactions between LTP and long-term memory are major issues of research. It has been shown that consolidation of memory can even be disrupted by new learning, but also by brain trauma, seizures, or by blockade of transcription or translation (Dudai, 2004). Moreover, disruption of stabilized memory traces may not only occur upon new learning, but also upon retrieval of stored information. Hence, memory retrieval is believed to induce a temporary period of lability that allows an existing association to be updated (Finnie and Nader, 2012). Consequently, the synapses storing the engram are destabilized, and undergo a period of deconstruction and protein degradation that makes the synapses malleable (Lee, 2010; Jarome et al., 2011). Nevertheless, also for these dynamic processes that undergo stabilization and destabilization, theoretical models of computation have been developed using fuzzy algorithms that result in about $39.7 \times 10^{12}$ possible fuzzy engrams in the human cortex (Lopez et al., 2006). Obviously, this is just a theoretical number of all the options. In real biological systems, they are markedly reduced to a limited range of possibilities by optimizations. The initial phase of the learning process is triggered or can be reinforced by LTP and depression (LTD), or by other experience-dependent electrophysiological events increasing the efficiency of transmission (Bank and Schacher, 1992). The resultant structural and functional changes of synapses and postsynaptic responses gave rise to the exploration of additional learning algorithms, one of which is the synaptic weight association training (SWAT) algorithm (Wade et al., 2010). It is an improvement of the spike timing dependent plasticity (STDP) algorithm that was combined with Bienenstock-Cooper-Munro (BCM) theory to implement a learning rule (Benuskova and Kasabov, 2007). The motivation to develop the BCM algorithm 
already very early on (Bienenstock et al., 1982) was exactly to take into consideration the "history" of a postsynaptic neuron. It is the notion, that synaptic input changes the characteristics of a synapse, and that the status of the postsynaptic neuron at any given time is a result of the inputs of its past. The term $\theta \mathrm{m}$, introduced in the BCM algorithm, entails a sliding threshold of synaptic modification that potentiates the synaptic weight, if the output frequency of the neuron exceeds $\theta \mathrm{m}$, and depresses the weight, when the frequency is below $\theta \mathrm{m}$. That means that LTD is induced by increased $\theta \mathrm{m}$ in the first case, and LTP is induced when $\theta \mathrm{m}$ is reduced in the latter case. This measure avoids to make the neuron unstable.

LTP has been investigated especially in pyramidal cells of the hippocampus, which attributes a crucial part of associative learning in a specific context to this brain region. Pyramidal neurons spontaneously generate EEG activity (Ventriglia, 2008). Small pyramidal neurons in layer $2-3$ of the cortex communicate with high beta or gamma frequencies, whereas layer 5 pyramidal neurons rather produce alpha and theta frequencies. A link between the theta rhythm and mechanisms of attention has been postulated (Vinogradova, 2001) because rhythmic oscillations in the theta $(4-15 \mathrm{~Hz})$, but also in the gamma $(20-80 \mathrm{~Hz})$ bandwiths are among the most prominent patterns of activity in attentional tasks (Buzsáki and Chrobak, 1995). Apparently, both rhythms encode essential aspects of hippocampal functions, as are learning and memory. Morphologically, they can be distinguished in local processes that are preferably associated with high-frequency oscillations in the gamma band, while long-range interactions rather synchronize at the lower frequencies of theta, alpha $(8-12 \mathrm{~Hz})$, and beta $(13-30 \mathrm{~Hz}$ ) bands (von Stein and Sarnthein, 2000; Siegel et al., 2012). Interestingly, networks oscillating at different frequencies can interact with each other by cross-frequency coupling (Figure 1) or phase-amplitude coupling. As a result, the power of gamma oscillations can be influenced by the phases of theta or alpha band oscillations (Canolty et al., 2006). Interestingly, recent data obtained from slices of neocortex also suggest interactions between spontaneously occurring delta rhythms in NonREMsleep and single action potentials at theta frequency (Carracedo et al., 2013). It is believed, that these stages of sleep support information processing and memory consolidation.

Most models are built on a learning rule that is able to infer the best or most likely weights, approaches broadly consistent with analogous events found in biology, such as LTP and LTD.

However, one important element known from chaos theory appeared to be missing in this learning rule, the notion of uncertainty, which is the main strength of a probabilistic approach described recently (Pouget et al., 2013). In contrast to use a point estimate of the weights, computing a posterior distribution over weights, or averaging over the weights would be more robust. In this context, the authors discuss models that entail rules for learning compositions of structures (structural learning) and suggest to start modeling with simple graphs and let the networks grow with increasing amounts of incoming observations and, hence, increasing complexity. In order to contain the sizes of the graphs and avoid that they reach limitations, a new set of neurons was used when a new node appeared. Although this measure may work well, it does not reflect the biology of the brain, where the appearance of new neurons is scarce. Another option would be to assume rewiring of neuronal networks with changing tasks. This also is unlikely, because the brain does not have the ability to rewire itself in a task-dependent manner. As a consequence, the structural learning process has to work with a more or less constant number of neurons and their synaptic plasticities.

Moreover, there exists another biological problem that needs to be considered in computer simulations: nonsynaptic or extrasynaptic events produced by moderate levels of synaptic plasticity (no LTP) (Saar and Barkai, 2003), adding a synergistic factor to synaptic events (Xu et al., 2005; Triesch, 2007). In the presence of long-term synaptic plasticity including LTP, robust levels of nonsynaptic activities could be generated acting as negative-feedback mechanisms to ensure network stability (Armano et al., 2000). These nonsynaptic activities can be localized in different compartments within the same neuron down to the level of single dendritic branches (Losonczy et al., 2008), extending the biological options to modulate neuronal network activities (Mozzachiodi and Byrne, 2010). In keeping with this, spiking events in dendrites have also been reported in response to action potentials generated in the soma/axon region of a neuron ("backpropagation") both in vitro (Stuart and Sakmann, 1994) and in vivo (Spencer and Kandel, 1961; Lee et al., 2006), which affected the induction of LTP (Letzkus et al., 2006). This stimulated the search for voltage-gated ion channels in dendrites. Sodium channels facilitating backpropagation have been identified in pyramidal neurons and may induce local action potentials (Losonczy and Magee, 2006). Furthermore, voltagegated $\mathrm{Ca} 2+$ channels of the L-, T-, and R-types and of the P/Q- and N-type (Markram et al., 1995; Kavalali et al., 1997; Bloodgood and Sabatini, 2007) have been studied in dendrites of various neuronal cell types. Spike backpropagation, local spike initiation and synaptic potentials likely are regulated by $\mathrm{K}+$ channels (Hoffman et al., 1997; Bekkers, 2000), a variety of which are expressed in dendrites. Additionally, voltage-dependent $\mathrm{Cl}^{-}$channels (Madison et al., 1986) and hyperpolarization-activated (h) channels (Pape, 1996; Lörincz et al., 2002; Kole et al., 2006) have been detected. Apparently, the spatial density gradient of $h$ channels along the dendrites displays resonance frequency maps, where inputs into different regions could become differentially filtered (Narayanan and Johnston, 2007). This filtering function can result in fine-tuning of neuronal oscillatory behavior. Gating of all these channels is highly dependent on their cellular environment and subject to regulation by phosphorylation/dephosphorylation both of which can occur within milliseconds but can also be stable for extended periods of time (Johnston and Narayanan, 2008). Moreoever, induction of synaptic plasticity could also be elicited by one trial of a conditioning, tonic depolarization of the resting potential, and followed by a second trial. Theoretically, these activities can be envisioned as many local, dendritic networks functioning along with some long-distance projections that together are reminiscent of so-called small-world networks first described mathematically by Watts and Strogatz (1998). Viewed from the systems level, the network of dendritic ion channels and their plasticity could be conceptualized alongside with synaptic plasticity. The integration of all these aspects of real biological systems into future models of learning theory and computational 
neuroscience requires quite some work in the years to come (London and Häusser, 2005; Kim and Linden, 2007; Tretter et al., 2010; Tretter and Gebicke-Haerter, 2012).

Along these lines, but distinct from those dendritic networks, specific dendritic networks connected by gap junctions have to be discussed (Bennett and Zukin, 2004; Connors and Long, 2004; Hormuzdi et al., 2004). These specific contacts, so-called electrical synapses, formed between neuronal dendrites are channels constructed by connexins (Frisch et al., 2005), encompassing important ways of cell-cell communication. They can be viewed as syncycial neuronal networks. A hemichannel inserted in one cell makes contact with a hemichannel of a neighboring cell, in this way not only allowing flux of ions, but also of additional small molecules from one cell to another. Hence, small synaptic proteins can enter neighboring synapses and mediate cross-talk between dendritic spines. Synaptic proteins are indeed shared between neighboring synapses (Gray et al., 2006). These dendritic networks are believed to be part of a synaptic engram (Tsuriel et al., 2006). Apparently, there are five different connexins (Cx26, Cx30.2, Cx31.1, Cx36, and Cx45), expressed in neurons of the brain (Venance et al., 2004; Vandecasteele et al., 2006; Kreuzberg et al., 2008). Connexin36 is the major neuronal connexin (Condorelli et al., 1998) expressed by GABAergic, fastspiking, parvalbumin-positive neurons throughout the mammalian brain. These neurons form gap junctions between their dendrites, or between their dendrites and somata (Fukuda et al., 2006). Moreover, gap junctions have been observed also in excitatory pyramidal neurons (Fukuda, 2007). This manner of cell-cell communication permits a much faster transfer of information than the well-known neurotransmission between pre- and postsynaptic domains. Gap junctional intercellular transmission has been found to be either bidirectional or rectifying (Phelan et al., 2008). However, gap junctional proteins and resultant cellular networks are not only expressed and maintained by neurons, but-equally important-expressed by glial cells, as discussed and extended below. There are even reports of gap junctional connections between glial cells and neurons (Alvarez-Maubecin et al., 2000). Activities through these networks could be reconciled with two models of clustered or dispersed plasticity in processes of learning and memory developed some years ago, that involve dendritic cross-talk following LTP or LTD either in random synapses of the dendritic arbor or concentrated in nearby synapses. In these models, the formation of an engram could be understood as the result of processes of enhanced synaptic protein synthesis in potentiated synapses connected by dendro-dendritic arborisations (Yuste and Urban, 2004; Govindarajan et al., 2006).

Obviously, these investigations on neuronal networks understand them as devices accepting and storing information in digital form, because of the well-known fact, that a neuron fires or does not fire. The brain, however, is not only composed of neurons. There are now numerous reports attributing a major function of information processing and storage to glial cells, to astrocytes, in particular. These cells, along with oligodendrocytes, are in intricate connection with neurons at their synapses and their axons, and astrocytes conduct electrical currents preferably on shorter distances and in more graded ways reminiscent of analogous processing elements. This is owed to the fact that the density of $\mathrm{K}+$ channels in astrocytes by far exceeds that of $\mathrm{Na}+$ channels, preventing the generation of glial action potentials. Therefore, it is attractive to presume that the brain exploits both the digital and analog ways of information processing and storage.

\section{GLIAL FINE-TUNING OF NEURONAL ELECTRIC ACTIVITIES}

The contribution of glial cells to the formation and maintenance of engrams has been largely ignored in the past. This important issue has only been discovered very recently, giving rise to a workshop held at the National Science Foundation in Arlington, Virginia, which assembled an international team of experts on learning and memory together with experts on glia (Fields et al., 2014). In contrast to the view held decades ago, that astrocytes are mere supportive elements of neuronal networks in the CNS (glia = glue), they are now recognized as important cells closely communicating with neurons and modifying their activities (Araque et al., 2001). As outlined below, astrocytes appear to be an important cellular interface to control and modify neuronal data processing and flow of information by their close physical contact with neuronal fibers (Clarke and Barres, 2013). During development of the CNS, they serve functions of guidance to migrating neurons and subsequently help in the elaboration of synaptic contacts by refinement and specialization of their fibers (Ullian et al., 2001). Apparently, this facilitation of synapse formation by contact of astrocytes with neurons is mediated by integrin-dependent signaling pathways (Hama et al., 2004). It raises the possibility that astrocytic networks with specific temporal and spatial characteristics of information processing closely interact with distinct information processing of neuronal networks. These features have been implemented in some simplified computational models of artificial neural networks to study the effectiveness of long term synaptic facilitation (Wallace and Bluff, 1995).

Astrocytic fibers intimately ensheath dendritic spines (Campbell and Shatz, 1992), adapt their motility to the behavior of dendritic spines and are able to rapidly elaborate contacts with or retract from the synapse (Haber et al., 2006). In this way, astrocytes get in direct contact with the released neurotransmitters (Derouiche et al., 2002) and mutually communicate by gap-junctions (Theiss and Meller, 2002) (Figure 2). This structural peculiarity gave rise to the concept of "tripartite" synapses, encompassing the pre- and postsynaptic neurons and the astrocyte. Recent observations revealed that calcium signals from astrocytes connected to those synapses are essential for their normal function (Tanaka et al., 2013). It has been reported, that processes from a single astrocyte can envelop up to 2 million synapses in the human brain (Oberheim et al., 2006) and approximately 140,000 synapses in rodents (Bushong et al., 2002). This salient feature of human astrocytes may result in superior cognition, learning and memory typical only for humans in the light of a recent study in mice using human astrocytes transplanted in the forebrain. These animals showed improved LTP and learning abilities (Han et al., 2013). Apart from the well-known uptake system for glutamate in astrocytes by glutamate transporters at glutamatergic synapses, their communication with neurons is also mediated by astrocytic G-protein coupled receptors (GPCRs) and Gq as the G-protein 


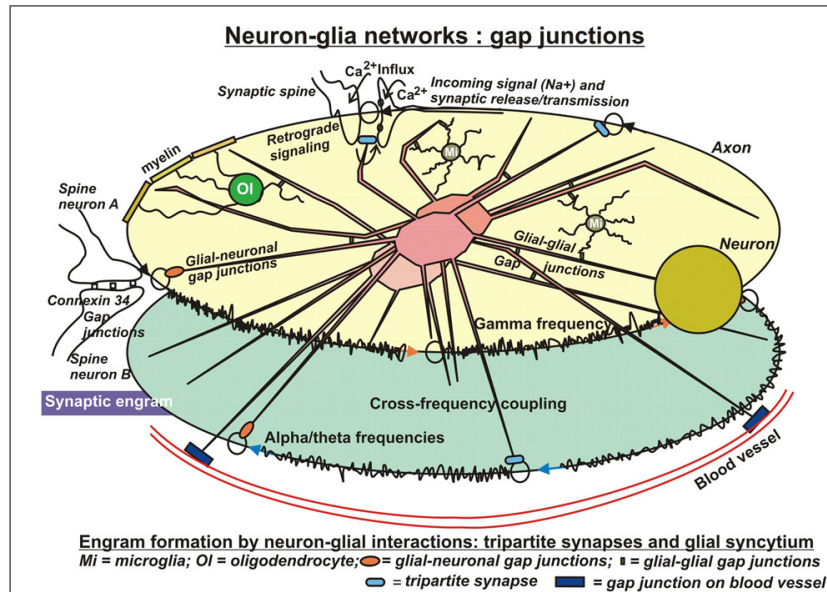

FIGURE 2 | In search for substrates of engrams. Evidently, the neuronal networks used in computational models are insufficient to reflect the biology of learning and memory. Clearly, the glial compartment of the brain is missing. Possibly the most important cell type in this respect is the astrocyte. Astrocytes are closely connected with most, if not all neuronal synapses, form a network with each other, the astrocytic syncytium, are connected with other glial cell types and additionally with the vasculature. The tremendous number of processes of human astrocytes (approximately 20 times more than rodent astrocytes) confers to them an ideal role in distribution and long-term storage of information. In particular, in sharp contrast to neuronal networks, the salient feature of these highly complex astrocytic networks of communication is their analog processing of incoming stimuli, because these cells do not produce action potentials. This allows for graded, fine-tuning of data processing and storage. Moreover, it permits modification or even control of neuronal network activities by neurotransmitter uptake, release, and retrograde signaling events. Conversely, activities of astrocytic networks are under control of neuronal input at synaptic clefts but also through connections by gap junctions. In conclusion, engram formation in the Central Nervous System presumably proceeds and consolidates by close interactions of two distinct but mutually complementing, cellular network systems. Unfortunately, information on the roles of other glial cell types in this respect are sparse. Oligodendrocytes may have substantial influence on neuronal electric properties by their tight contacts of myelin with axons, and microglia appear to modify astrocytic activities as well as synaptic neurotransmission upon inflammatory stimuli. Additionally, microglia may influence neurotransmission under normal conditions, which gave rise to the notion of a "quad-partite" synapse.

responsible for astrocytic $\mathrm{Ca} 2+$ elevations. These receptors enable astrocytes to respond to additional neuroligands (Shelton and McCarthy, 2000; Perea and Araque, 2005) by elevations of intracellular Ca2+ (Dombeck et al., 2007; Bekar et al., 2008) and enable this cell type for information processing and storage (Perea and Araque, 2006). In the absence of neuronal stimuli, most astrocytes in hippocampus, cortex, and thalamus also exhibit spontaneous Ca2+ oscillations (Aguado et al., 2002; Nett et al., 2002). These oscillations are synchronized upon rises of neuronal activities in neuronal networks (Aguado et al., 2002). As a matter of fact, astrocytes respond to synaptic activity by local discrete calcium transients that occur on a similar time scale to that of synaptic activity (Panatier et al., 2011). In 1994, Haydon et al. (Parpura et al., 1994) made the seminal observation in cultured astrocytes, that increased intracellular $\mathrm{Ca} 2+$ concentrations $([\mathrm{Ca} 2+] \mathrm{i})$ induce release of glutamate. This finding has been confirmed lateron in vivo. This in turn implies that the release of gliotransmitters might lead to the synchronization of neuronal firing patterns (Fiacco and McCarthy, 2004). Indeed, astrocytes activated by neurotransmitters may in turn release glutamate into the synaptic cleft and activate postsynaptic neuronal glutamatergic receptors (Angulo et al., 2004; Fellin et al., 2004; Jourdain et al., 2007). Hence, astrocytic Ca2+-elevations transiently can increase the synaptic efficacy. Along these lines, it has been shown that astrocytic release of glutamate synchronously activated neighboring neurons through extrasynaptic NMDA receptors in CA1 of the hippocampus (Angulo et al., 2004; Fellin et al., 2004). These authors showed that the synchronization by glial cells was activated by neuronal activity itself, which suggests the existence of a reciprocal neuron-glia regulatory feedback loop. It is important to note, that this synchronous activation was spatially restricted to neurons with less than $100 \mu \mathrm{M}$ separation, which would assume a regional glial network that conveys a spatially limited degree of synchronization. In addition to glutamate, astrocytes have been shown also to release D-serine, an unusual amino acid produced from L-serine by serine racemase. It has been reported recently, that the release of this amino acid by astrocytes in the hippocampus was crucial for the induction of NMDA-dependent LTP (Henneberger et al., 2010), challenging for the first time the neuro-centric concept of LTP. It is a confirmation of earlier reports on direct stimulation of single astrocytes in the hippocampus (Perea and Araque, 2007) and in the hypothalamus (Gordon et al., 2009) that resulted in prolonged potentiation of synapses (Todd et al., 2006). Optionally, astrocytic Ca2+-elevations can also enhance the probability of presynaptic release $(\mathrm{Pr})$ rather than influence postsynaptic elements or extrasynaptic receptors. Indeed, it was shown that the synaptic potency was unchanged in the presence of increased Pr after astrocyte stimulation (Perea and Araque, 2007). In keeping with this, astrocytes apparently can also inhibit Pr and serve a "buffering" function on synaptic activities, the so-called "glial scaling." In this process, that proceeds within hours to days, the firing rates of a neuron are maintained in an optimal range by scaling the strengths of all synaptic inputs to that neuron up or down to balance out the relative intersynaptic differences in efficacy. Without such compensatory scaling, an increase in synaptic efficiency would rapidly reach saturation of neuronal firing rates and disable the neuron's responses to changing stimulation patterns. Conversely, a decline in synaptic strength would reduce the neuronal probability to pass the threshold for triggering an action potential and, in consequence, silence the neuron (Fregnac, 1998; Feldman, 2002). Collectively, those data suggest that only few astrocytes are involved in local, homosynaptic modulation and plasticity, not requiring communication within a glial network, whereas heterosynaptic events encompass glial communication via a glial syncytium (Ben Achour and Pascual, 2010).

Such a functional syncytium with communicative behavior is composed of astrocytes coupled together by gap junctions. However, there is also some evidence for significant neuronglia gap-junctional coupling in a few brain regions (Figure 2). Those gap junctions help to coordinate cell firing in neuronal networks and adjust metabolic and transcriptional activities between 
coupled neurons and astrocytes (Dere and Zlomuzica, 2012). Recently, Pannasch et al. (2011) showed that coupled astrocytes are involved in synaptic transmission at CA1 pyramidal cells. Here, astrocytic gap junctions mediate extracellular glutamate and potassium removal during synaptic activity, modulate neuronal excitability and neurotransmitter release, and participate in the insertion of postsynaptic AMPA receptors. Moreover, they can change morphology and turnover of neuronal spines through interaction of their ephrin3 with ephrin A4 (EphA4) receptors on spines (Murai et al., 2003; Slezak et al., 2006). These results suggest that astrocytic gap junctions in the hippocampus play an important role in the regulation of both synaptic transmission and plasticity and possibly memory formation (Rouach et al., 2008; Pannasch et al., 2012; Escartin and Rouach, 2013). Collectively, this would be an exciting field for computational neuroscience and modeling. Unfortunately, until now, little efforts have been undertaken to include astrocytes and other glial cell types into computational approaches.

Astrocytic gap junctions are mainly formed by connexins 43 and 30 (CX43 and CX30, respectively) in a cell type-specific fashion (Nagy and Rash, 2000). Connexins 30 are the main proteins mediating intercellular coupling between radial glial cells in the adult dentate gyrus (Kunze et al., 2009), whereas Cx43 is the main constituent of the brain-spanning astrocytic gap junction network (Yamamoto et al., 1992). Another connexin expressed in astrocytes is Cx26 (Koulakoff et al., 2008). In the human genome, 21 and in the mouse genome 20 different connexin genes have been found, coding for distinct connexin proteins (Willecke et al., 2002). A gap junction channel consists of two hemichannels (connexon) which are contributed by two neighboring cells. Each connexon is composed of six connexin proteins.

Gap junction channels formed by connexins mediate the propagation of intercellular $\mathrm{Ca} 2+$ waves. Moreover, through these cellular networks, astrocytes can exchange molecules, such as K+ or glutamate (Rottingen and Iversen, 2000), or permit the intercellular, bidirectional diffusion of nutrients, of other ions, metabolites, or second messengers, such as Ca2+, cAMP, IP3, and more small molecules of up to one $\mathrm{kDa}$ or less than $16^{\circ} \mathrm{A}$ in diameter (Dobrowolski and Willecke, 2009). The gating of gap junction channels in the brain is regulated dynamically (Giaume and McCarthy, 1996). They are able to vary their conductance (Yang et al., 1990), their subunit composition, the number of cell contacts and show activity-dependent plasticity. Changes of channel conductance depend on transjunctional voltage, intracellular $\mathrm{Ca} 2+$, on intracellular $\mathrm{pH}$, on sodium and magnesium concentrations, on phosphorylation or cytokines (Dermietzel, 1998; Salameh and Dhein, 2005). For instance, phosphorylations of $\mathrm{Cx} 43$ by protein kinases including mitogen-associated protein kinase (Warn-Cramer et al., 1998), protein kinase C (Lampe, 1994) or tyrosine kinase (Loo et al., 1995) exhibit strong influences on the astrocytic gap junctional network. Phosphorylation of Cx43 induces the uncoupling of cells and suppresses gap junction-mediated intercellular signal transfer. Apparently, this transfer from astroglia to neurons through $\mathrm{Cx} 43$ hemichannels is required to consolidate fear memory (Sáez et al., 2003; Stehberg et al., 2012).
The electrical properties of gap junctions coupling hippocampal astrocytes are distinct from those of electrical synapses between neurons (Meme et al., 2009). In contrast to neurons, activation of GABAA receptors in astrocytes causes $\mathrm{Cl}^{-}$efflux, which results in astrocytic membrane depolarization (Bekar and Walz, 2002). This receptor-mediated depolarization induces a rise in cytosolic $[\mathrm{Ca} 2+] \mathrm{i}$ (Meier et al., 2008). With higher $\left[\mathrm{Cl}^{-}\right] \mathrm{i}$, GABA application can mediate bidirectional $\mathrm{Cl}^{-}$fluxes in astrocytes, $\mathrm{Cl}^{-}$efflux via GABAA receptors, and $\mathrm{Cl}^{-}$influx along with GABA uptake via GABA transporters. GABAA receptormediated currents are propagated via gap junctions within the astrocytic network. The suggested mechanism: GABA spillover activates astrocytic GABAA receptors localized near the synaptic clefts, and their signals propagate to neighboring astrocytes via gap junctions. Such homeostatic dynamics of $\mathrm{Cl}^{-}$within the astrocytic network might contribute to maintain efficient neuronal GABAergic transmission by regulating $[\mathrm{Cl}-]_{\mathrm{o}}$ (Egawa et al., 2013). These examples convincingly show, that the (astro-) glial syncytium should not be considered as a separate cellular system, but rather as intimately intertwined with neuronal networks. In other words, astroglial wiring is influenced by neurotransmitters, or peptides released by neurons, or by cytokines and endogenous lipids, released by other brain cell types, including microglia and endothelial cells (Giaume et al., 2010). Overlaps of these networks with functional units of neurons have been shown in the somatosensory cortex (Houades et al., 2008) and the glomerular layer of the olfactory bulb (Giaume et al., 2010).

Under the view, that coupled astrocytes can communicate with each other via the propagation of calcium waves and with surrounding neurons via the release of neurotransmitters (such as glutamate), as well as through other extracellular signaling molecules (such as ATP), possibly released through connexin43 hemichannels (Kang et al., 2008; Stehberg et al., 2012), it is evident that they play a much more active role in information processing and higher cognitive functions than previously assumed (Fields and Stevens-Graham, 2002; Nedergaard et al., 2003). In keeping with this, ATP does not only serve as a source of energy supply, but also as a ligand for purinergic receptors that induce a rise of intracellular calcium to expand transglial waves in local neural circuits (Hoogland et al., 2009). This increase of intracellular calcium via $\mathrm{P} 2 \mathrm{Y}$ receptors also controls transmitter release by induction of heterosynaptic LTD in the CA1 region of hippocampus, in this way keeping at bay ongoing LTP (Chen et al., 2013). Therefore, in addition to memory storage by neuronal networks, mutual interactions between glial and neuronal networks may increase the efficiency to organize memory, and substantially extend storage capacities.

Furthermore, there is close contact of astrocytes with blood vessels via gap junction proteins that decorate blood vessel walls (Figure 2). These astrocytes form a physical link between the vasculature and synaptic terminals. It is a network subserving a metabolic supportive function by facilitating glucose delivery from the blood to neurons. In this network, again, the astrocyte is not a passive element but metabolizes glucose into lactate and releases it to sustain neuronal synaptic activities (Pellerin et al., 2007; Pellerin and Magistretti, 2012). As reported by Suzuki et al. (2011), a transient disruption of the flow of energy 
substrates from astrocytes to neurons severely interferes with subsequent formation of long term memory, although it does not markedly affect learning. This complementary network supposedly is extremely important in pathological conditions such as hypoglycemia or hypoxia to ensure neuronal survival, because in those conditions gap-junctional channels are still functional (Cotrina et al., 1998). Most importantly, however, the lactate derived from glucose or glycogen is pivotal in non-pathological conditions, where it is required for learning and memory (Suzuki et al., 2011).

Finally, it has to be mentioned, that the glial network of information processing and storage not only encompasses astrocytes, but also other glial cell types. For example, oligodendrocytes form heterotypic gap junctions with astrocytes in vivo consisting of $\mathrm{Cx} 32$ and $\mathrm{Cx} 47$ at the oligodendrocyte and $\mathrm{Cx} 30$ and $\mathrm{Cx} 43$ at the astrocytic side, constituting part of a panglial network. And oligodendrocyte-oligodendrocyte gap junctions have been observed, as well (Nagy et al., 2011; Wasseff and Scherer, 2011). The panglial gap junctions, in particular, appear to be essential for maintenance of normal myelin (Tress et al., 2012). Moreover, even subtle disturbances of the intimate contact of oligodendroglial myelin membranes with neuronal fibers can change conduction velocities, with ensueing alterations in the oscillatory behavior of neuronal networks (Pajevic et al., 2013). In inflammatory or hypoxic conditions, this network seems to be extended to connections with microglia that are also able to communicate via gap junctions (Eugenín et al., 2012). These cells may participate in eliminating synapses (pruning), but also in facilitating new synaptic contacts under non-inflammatory conditions. Hence, normal synapses have been considered very recently as composed of four distinct cells, the pre- and postsynaptic neurons, the astrocyte and the microglial cell, named the "quad-partite" synapse (Schafer et al., 2013).

\section{MOLECULAR BASIS FOR MEMORY FORMATION Synaptic restructuring and translation}

Memory is in significant part a molecular process through which learned information is stored (Klann and Sweatt, 2008). Until now, relatively little is known about the formation of molecular engrams. Research on changes on the molecular level specific for memory have predominantly focused on molecules involved in synaptic plasticity.

The synaptic tagging and capture hypothesis (Frey and Morris, 1997; Redondo and Morris, 2011) includes a functional change in synaptic strength of an activated synapse accompanied by a temporary structural remodeling of the cytoskeleton resulting in the exposition of local (dendritic) tags and involving a large number of proteins and their interactions. Simultaneously, the synthesis and distribution of plasticity-related proteins ( $\mathrm{PrPs}$ ) is upregulated. Neither the functional nor the structural changes will persist without the supply and incorporation of new PrPs. Only if these proteins are captured in some specific way by the tags, a memory trace can be consolidated. A tagged synapse that has received PrPs, will stabilize its new structural conformation before the tagging state fades and so maintain its change in synaptic efficacy. The structural remodeling of the spine including the actin network, and the role of CaMKii required for tagging, therefore, seem to be necessary but not sufficient conditions for the expression of long-term (L)-LTP (Lang et al., 2004; Redondo et al., 2010). There is an initial increase in the number of AMPA receptors inserted into the available post synaptic density (PSD) slots of existing dendritic spines. In the case of early (E)-LTP, the number of release sites and AMPA receptors gradually return to baseline levels. By contrast, for L-LTP, the supply of PrPs anchors the additional AMPA receptors via new PSD slots, that are matched by a sustained and complementary increase in release sites. Eventually, remodeling of spine structure results in an increase (L-LTP) or decrease (L-LTD) in the number of slots available for AMPA receptors, and a corresponding presynaptic change in vesicle release sites (Lisman and Raghavachari, 2006).

Possibly subtle, local changes in the rates of synthesis of a variety of proteins are sufficient for memory consolidation. This leads us to another notion raised some years ago, that only a small but functionally effective localized, quantitative change in specific protein translation is necessary to induce transient, short-term memory that is then stabilized by positive feedback mechanisms requiring only minimal ongoing constitutive protein synthesis (Bailey et al., 1989; Kelleher et al., 2004). It is assumed that these events occur locally at a dendritic spine, and that the process is NMDA receptor-dependent. The primary site of translational control is the initiation step of binding the mRNA to the small $40 \mathrm{~S}$ ribosomal subunit and its positioning to the initiation codon. A decline of translation initiation occurs upon phosphorylation of the $\alpha$ subunit of the initiation factor eIF2 at Ser51, which prolongs its association with eIF2B and consequently inhibits GDP/GTPexchange (Sonenberg and Dever, 2003). There is some evidence, that phosphorylation of this factor influences L-LTP and contextual fear conditioning (Costa-Mattioli and Sonenberg, 2006). Another factor investigated in this respect is mechanistic target of rapamcyin (mTOR) and its effector molecules (Graber et al., 2013a,b). It has been reported recently that memory consolidation during sleep is mediated by the mTOR pathway (Seibt and Frank, 2012).

\section{Epigenetics and transcription}

Very unlikely, changes on the genome level have substantial influence on the formation of engrams, because the relative stability of the genome does not allow for the required, rapid adaptations to environmental challenges. Therefore, factors controlling transcription are amongst the first to consider in the present context. The available literature strongly supports the notion, that altered transcription is a necessary component at least for the longestlasting forms of synaptic plasticity and memory (Figure 3). The "classical" way to regulate transcription is by the action and interactions of transcription factors. In the light of epigenetic influences, their binding to respective, specific responsive elements on DNA is, at least in part, dependent of those prior DNA modifications. Nevertheless, quite some transcription factors have been identified to be required for short- and long-term memory, as well. These include several immediate early gene products, such as the transcription factor CCAAT enhancer binding proteins (C/EBPs), c-Fos, and Zif268, as well as effector gene products such as activity-regulated cytoskeletal protein (Arc) and tissue-plasminogen activator (TPA) (Melchor and Strickland, 


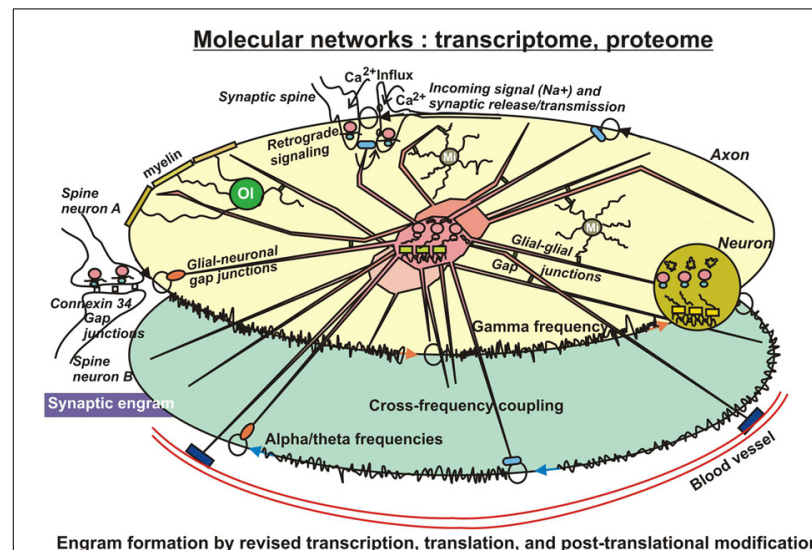

Engram formation by revised transcription, translation,

FIGURE 3 | In search for substrates of engrams. Eventually, patches of memory, or engrams have to be laid down in structural details of molecules. Significant modifications on that level include transcriptional, translational, and post-translational adaptations to environmental impact. Adverse external influences can result in changes of DNA and histone modifications (epigenetics), with consequent changes of transcription, in altered translation, and in a wealth of readjustments of secondary or tertiary modifications of protein structures, actions that can even occur in pre- or postsynaptical sites, where ample polysomes have been identified, prepared for fast responses to new challenges. These subtle structural modifications of molecules appear to be best suited as physical entities for engram formation. Their covalent bonds ensure stability for extended periods of time, but nevertheless entail the option to be reversible. Interactions of those "memory" molecules within their molecular networks introduce long-term, but slow adaptations with far-reaching long-term consequences, such as altered ion channel conductances, altered synaptic mobility or release properties, or modified astrocytic lactate supply of neurons under hypoxic stress. The sustained, dynamic interactions of the organism with its environment further imply additional exposures of these molecular mechanisms to both favorable and adverse influences, which can result in compensation of prior adverse modifications or in reinforcement of existing adverse modifications by more modifications. This notion conforms with the concept of schizophrenia and other mental illness to develop by accumulation of repeated insults afflicted by negative, environmental conditions.

2005; Alberini, 2009). In nucleus accumbens, overexpression of the transcription factor CREB increases overall excitability of neurons by enhancing the $\mathrm{Na}+$ current while suppressing the $\mathrm{K}+$ current (Dong et al., 2006). Furthermore, CaMKii $\beta$ could act on a pool of actin to mediate spine expansion (Sanabria et al., 2009). This polymerization of F-actin has been visualized via live imaging within single dendritic spines (Ahmed et al., 2006). Brain derived neurotropic factor (BDNF) is another factor inducing a whole array of genes. At least part of them are believed to be associated with learning and memory (Liao et al., 2007). Evidently, these approaches are rather searching for influences of single gene products, but are not driven by a systems biological concept trying to find molecular networks working in concert to shape and consolidate long-lasting memory.

Important control mechanisms for transcriptional rates are modifications of DNA (methylations) and of histone proteins, commonly subsumed under epigenetics. Many of those modifications are introduced in response to environmental influences and can be considered as fine-tuning mechanisms of gene expression.
They can produce short- and long-lasting, quantitative changes in gene expression that might serve as mechanisms to erase or consolidate traces of memory. Accordingly, a number of recent studies have focused on the role of epigenetic changes in memory formation and storage (for review, Jarome and Lubin, 2013; Zovkic et al., 2013). Epigenetic control of transcription serves as a means to maintain increased or decreased levels of specific proteins associated with engram formation at the synapse or in other cellular compartments. Changes in methylation have been identified as a possible maintenance mechanism of memory, partially because these changes are relatively stable over time. DNA methyl-transferase (DNMT) 1, for example, appears to actively maintain at least some existing methylation patterns (Law and Jacobsen, 2010; Zovkic et al., 2013). It does not mean, however, that methylations are not reversible. An example of the fine-tuned repression/derepression of a gene by methylation has been described by Miller and Sweatt (2007). The suppression of memory traces has been observed in association with the activity of protein phosphatase 1 (PP1). One result of PP1 activity is the methylation of the promoter of the Reelin gene. The Reelin protein reportedly is involved in long-term memory formation (Weeber et al., 2002). Upon methylation of the PP1 promoter by DNMT1, normal memory is restored along with demethylation of the Reelin promoter by an as yet ill-defined demethylase. However, as mentioned in the Introduction, shortterm memories may be transferred from the hippocampus to the cortex for long-term storage. Correspondingly, it has been shown, that in early memory tasks methylation of the Reelin promoter is rapidly reduced in hippocampus, but reconstituted to normal within $24 \mathrm{~h}$. By contrast, reduced promoter methylation persists for extended periods of time in areas of the prefrontal cortex (Miller and Sweatt, 2007; Sui et al., 2012). This example is mentioned to indicate that kinetics, duration, and readout of DNA methylations and demethylations vary in different brain regions, cell types, and genes, and may be important molecular traces of wide-spread distribution of long-term memory in the brain. Therefore, investigations on genome-wide methylation patterns in different brain regions at different times after a learning task could reveal changes in transcriptional networks guiding to gene products involved in engram formation. It is currently unclear whether other epigenetic mechanisms, such as histone acetylations and nucleosome remodeling are involved in memory maintenance. There is ample evidence, however, that changes of histone methylation occur in concert with DNA methylation in the adult CNS. Histone lysine methylation, for example, which can either activate or repress gene expression depending on the number of methyl groups associated with a specific lysine residue, has been shown to be dynamically regulated following context fear conditioning (Gupta et al., 2010). In this behavioral learning paradigm, long-term down-regulations of histone $\mathrm{H} 3$ lysine 4 trimethylation (H3K4me3) have been observed in the entorhinal cortex $24 \mathrm{~h}$ after the learning task (Gupta-Agarwal et al., 2012). It would be interesting to identify all the genes that are affected by these trimethylation changes in these conditions and construct a transcriptional network. The observation that histone modifications are subject to faster turnover than DNA methylations is reminiscent of the considerable dynamics of this molecular 
system, that is additionally paired with a tremendous complexity contained in the innumerable combinations that are possible to tag histone tails. More details of histone modifications are discussed below, because they belong to issues of post-translational modifications (PTMs). These types of epigenetic changes appear to encode short-term rather than long-term memory formation. But, apparently, we are far away from understanding the multiple subtle alterations in the molecular patterns of the astounding network of the epigenetic code. A more thorough update of these mechanisms is being provided in an accompanying paper (Sananbenesi and Fischer, in review).

Finally, it has to be noted, that transcription of mRNAs does not necessarily need to be confined to the neuronal cell body. In 1982, Steward and Levy reported on the occurrence of polyribosomes in dendrites and spines of hippocampal pyramidal neurons, meaning that mRNAs are protected from degradation by binding to ribosomes in the cell body and transported on microtubules to postsynaptic sites of dendrites or to axon terminals (Figure 3), where the above mentioned plasticity-related proteins (PrPs) could be synthesized directly on demand. Using microarray technology, Eberwine et al. (2002) and Matsumoto et al. (2007) have identified hundreds of mRNAs in neuronal dendrites, confirming the possibility of local protein translation (Martin and Zukin, 2006). Those polysomes provide the synapse with a fast mechanism to translate mRNAs in that specific compartment of the neuron into functional proteins in response to neuronal activities (Graber et al., 2013a,b). Microarray analyses of transcripts and of translated proteins on genome-wide levels likely hold promising potential to identify molecular substrates of engrams, in particular, if they are conducted and combined on temporary scales.

\section{Post-translational mechanisms}

Consolidation of short-term memory probably requires protein synthesis and PTMs, as well (Figure 3). PTMs have been studied in a wide range of proteins including the histones. These proteins can be Lys acetylated, mono-, di-, or trimethylated, biotinylated, ubiquitinylated, NEDDylated, SUMOylated; Arg methylated; Ser/Thr/Tyr phosphorylated; and Glu ADP ribosylated all occurring within 50-100 residues on the N-terminal and Cterminal tails of $\mathrm{H} 2 \mathrm{~A}, \mathrm{H} 2 \mathrm{~B}, \mathrm{H} 3$, and $\mathrm{H} 4$ (Bhaumik et al., 2007; Latham and Dent, 2007), which is additionally paired with a tremendous complexity contained in the innumerable combinations that are possible through these modifications (Histone Code). Histone phosphorylations and their interactions have been studied extensively. They can be considered as logic gates (Lim, 2002) consisting from "write," "read," and "erase" PTMs (Lim and Pawson, 2010), where the kinases are the writers, phosphatases are erasers and protein-protein interactions are mediated by modular domains (e.g., SH2 domains) that bind to a tyrosine- or serine-/threonine-containing linear motif, in this manner reading the phosphate tags. There are large numbers of phosphate transferases ( $>500$ protein kinases) and large numbers of hydrolases ( $>140$ protein phosphatases). Very often, histone tails are phosphorylated at more than one amino acid. Theoretically, if the two sites are phosphorylated by different protein kinases, this configuration could provide a logical AND gate in a downstream response. In general, protein kinases exhibit quite strong selectivity for the primary sequence around the residues that they phosphorylate. Therefore, the presence of multiple PTMs and the new binding motifs that they form could result in lower specificity requirements for writer domains. If this is a general principle, it provides an important mechanism for decoupling catalytic activity from specificity in proteins: catalytic domains could focus solely on their catalytic function, while other domains would specifically bind to the substrate of the catalytic reaction. Furthermore, phosphorylation can prevent or promote Lys acetylation or methylation and vice versa. Another example is acetylation and methylation of histine $\mathrm{H} 3 \mathrm{~K} 9$, which are mutually exclusive, providing an example of direct competition. The histone $\mathrm{H} 3 \mathrm{~N}$-terminal tail can be simultaneously methylated at $\mathrm{K} 4$ and acetylated at five different lysines (K9, K14, K18, K23, and K27) (Taverna et al., 2007). Furthermore, methylation and ubiquitination can stimulate Lys acetylation, and SUMOylation antagonizes histone acetylation. There are more indirect effects of phosphorylations on other modifications. Phosphorylation of $\mathrm{H} 3 \mathrm{~S} 10$ prevents recognition of $\mathrm{HP} 1$ chromodomain of $\mathrm{H} 3 \mathrm{~K} 9 \mathrm{~m} 3 \mathrm{e}$; conversely, a chromodomain bound to $\mathrm{H} 3 \mathrm{~K} 9 \mathrm{me} 3$ precludes phosphorylation of S10. Hence, in this example one protein connects different PTMs on two histone tails (Ruthenburg et al., 2007). Most importantly, these examples imply a dynamic component. Post-translational protein phosphorylations have also been studied specifically focusing on the role of PKM $\zeta$ (Pastalkova et al., 2006; Kelly et al., 2007). PKM $\zeta$ overexpression has been demonstrated to enhance memory (Shema et al., 2011), suggesting that $\mathrm{PKM} \zeta$ indeed plays a role in memory stability (Kwapis and Helmstetter, 2013). PKM $\zeta$ is known to increase AMPA receptor trafficking to the synapse to actively maintain potentiation (Yao et al., 2008). Furthermore, following a learning event, the cytoskeleton is rearranged to establish strengthened connections in activated synapses, including changes in AMPA receptor expression at the postsynaptic density. In this context, other protein kinases are discussed as well. For example, PKC $\lambda / \iota$ has been shown to be responsible for AMPA receptor phosphorylation and synaptic incorporation during LTP (Ren et al., 2013). Together, these studies suggest that increases in PKM $\zeta$ and cytoskeletal rearrangement work in concert to maintain LTP. "Writer," "reader," and "eraser" functions, as described above for histones have been assigned to the components of many other PTMs in non-histone proteins (Seet et al., 2006). For instance, it has been shown that two or more phosphorylation sites in a protein can have a combinatorial effect on activity. Proteins primed through phosphorylation by one protein kinase are often phosphorylated processively on the N-terminal side of the priming phosphate by GSK3 at a series of Ser/Thr spaced by three residues, with the cluster of phosphates regulating protein activity (e.g., glycogen synthase, beta-catenin). There is also extensive use of acetylation, methylation, phosphorylation and other PTMs in nonhistone proteins, resulting in positive or negative regulation. For example, positive regulation would result through acetylation of a protein that depends on whether this protein has been phosphorylated (primed, see above), hydroxylated or ubiquitinated beforehand. An example of negative regulation (a PTM competing with phosphorylation) would be the attachment of 
O-linked $\mathrm{N}$-acetylglucosamine residues, which are coupled to specific Ser/Thr in many types of proteins, with transcription factors being prominent (Hart et al., 2007). Negative crosstalk of any sort between different PTMs can in principle be used as an OR logic gate in a signaling network. Unfortunately, very often it is not known whether different sites on an individual protein molecule are simultaneously modified. Consequently, determinations of all PTMs coexisting on a single molecule-and their changes over time are warranted.

The notion that engrams are formed and stored in defined neuronal cell populations as more or less permanent entities after a consolidation process resulting in increased synaptic strength (Liu et al., 2012), has been challenged vigorously since a long time (Routtenberg, 2013). As proposed more than 40 years ago (Routtenberg, 1972), information storage and retrieval emerges from a reciprocal, rapidly oscillating interaction among competing processes to permit the semblance of co-occurrence. In consequence, the hypothesis was put forward, that stable memories do not require stable synapses. Stabilization of synapses would even be contraproductive, because it prevents the physiological malleability of brain circuitry that is essential for proper memory retrieval. Stabilization of synapses, therefore, interferes with the construction of long-lasting memory. In other words, there is no long-term storage of memory, no dual traces, but rather a multiple representation of prior events by dynamic, self-reinforcing but impermanent networks (Routtenberg, 2008a,b). This notion has been supported by convergent findings some time ago using resolution imaging of dendritic spines that reveal dynamic, ongoing structural flexibility measured in seconds (Matus et al., 2000). The migratory habits of synaptic proteins indicate that the molecular composition of synapses is in flux, and the molecules themselves are subject to (secondary/tertiary) modifications in a sustained updating according to environmental input. Synapses, hence, are not stabilized by LTP, as posited in the long-standing concept, described above, but undergo sustained reshaping morphologically and very likely also in their functions depending on the incoming stimuli. From these data and the PTM hypothesis developed in parallel, it can be concluded, that the central Hebb dogma that cells that "fire together, wire together" is very unlikely to hold for establishing long-term memory. Instead there are mutually self-regulating molecular modifications and molecular networks on pre- and postsynaptic sites that are rapidly oscillating. The status of the PTMs is dependent on the activity of the network. To this end, synapses and engrams are "stabilized" by regulated feedback mediated by the circuit in which the synapse is embedded. This ensures that at any given time new learning information can be inserted into existing networks by subtle changes of PTMs. Furthermore, if we extend our view to the involvement of glial cells and their molecular repertoire, PTMs in glial cells should also play important roles in memory formation. Phosphorylations and ubiquitinations are amongst the most studied PTMs in gap junction proteins. For example, phosphorylation of $\mathrm{Cx} 43$ turned out to be extremely complex and, hence, can be used for fine-tuning of channel properties. It includes at least 21 different phosphorylation sites and a growing list of more than 10 different kinases and phosphatases. But also SUMOylations, nitrosylations, hydroxylations, acetylations, methylations, and $\gamma$-carboxyglutamations, regulating their open probability, conductance and selectivity, have also been identified. Although there are many $S$-nitrosylation sites in proteins, only few of them appear to be used for this modification. Notably however, because ischemia and/or hypoxia are associated with an increased production of NO, the increased hemichannel permeability of $\mathrm{Cx} 43$ has been associated with $\mathrm{Cx} 43 \mathrm{~S}$-nitrosylations (Retamal et al., 2006). Hence, $S$-nitrosylations play an important role in regulating hemichannel permeability in astrocytes (Retamal et al., 2009). Cx43 can also be directly acetylated, adding another option of gap junctional regulation in astrocytic networks (Axelsen et al., 2013).

In summary, this model entails mechanisms involving positive feedback, protein synthesis, and PTMs, in an integrated fashion, and it is the interplay of the three mechanisms that allows memory storage. The post-translational level, in particular, appears to be of major importance in terms of engram formation. Changes on that level encompass covalent molecular modifications, that are relatively stable over extended periods of time, but are reversible, as well. Hence, it is an ideal playground of nature to store, to select and discard, and to refresh memory for any period of time. The huge versatility of PTMs can affect conduction characteristics of sodium-, potassium-, and other ion channels, gap junctional permeabilities, hence the network properties discussed above, and properties of receptors, structural proteins, enzymes and of innumerable other molecules in subtle and specific ways, that it is feasible to identify pivotal cues of memory formation on that level. It could even be, that long-term storage of information exclusively is confined to post-translational mechanisms (Routtenberg and Rekart, 2005). As a matter of fact, the combinatorial variability of PTMs has been dubbed recently as the PTM code (Hunter, 2007; Creixell and Linding, 2012; Minguez et al., 2012, 2013). Supposedly, not everything is in the genes, but much is in the proteins.

\section{The temporary aspect}

In the view that consolidation of memory develops during time and memories are not absolutely stable, even on a long-term basis (Alberini, 2011), high throughput technologies used to investigate engram formation at various time points are necessary and probably the best way to eventually obtain the required insights. Undoubtedly, these approaches would require tremendous efforts considering the different time-scales of short- and long-term memory, and the different brain regions tentatively involved. Moreover, presumably there are distinct qualities of memory in experimental animals, which are the organisms of choice for those experiments, compared to human beings. A possible simplification of technological conditions may be, that no sophisticated methods are required to investigate down to single cell levels. Concluding from the above said, that molecular systems from glial cells and neurons closely interact in memory formation, analyses of molecular networks of cellular ensembles supposedly reveal better insights in their specific interactions.

In summary, the search for molecular substrates of engrams is still in its infancy, owing to the greater complexity of molecular systems compared to electrical circuitries of neurons or neuron-glial hybrid networks. Until now, approaches are mostly 
hypothesis-driven and focused on single candidate molecules located in synapses. It is clear, however, that engrams are composed of molecular networks, changed and modified by environmental factors, that continue to influence each other over time and are additionally modified by new networks growing from sustained environmental impact-processes maintained during the whole life of an organism. The identification of such molecular ensembles is the challenge of the years to come.

\section{BRAIN PATHOLOGY AND ENGRAM FORMATION}

After having revisited the existing knowledge from literature about different ways and different levels of construction, consolidation, and long-term storage of memory, we want to relate these insights to tentative mechanisms leading to chronic psychiatric disorders with focus on schizophrenia. One of the most popular hypotheses of schizophrenia is the neurodevelopmental hypothesis that posits an induction of the disorder during pregnancy or around birth. Nevertheless, it takes many years until a reliable diagnosis can be made. The progression of the disorder goes unnoticed until early adulthood, which entails a slow but steady accumulation of subtle, adverse events during development of the brain. Clearly, these adverse (environmental) influences are distinct between affected individuals and, therefore, result in formation of patterns of engrams characteristic for the disorder in their sum, but distinct in each patient. Consequently, despite common traits, histories and outcomes of schizophrenia are individually distinct. This entails the tacit agreement, that a genetic predisposition is of minor importance compared to environmental impact. The predominant influence of environmental factors is also widely accepted for other mental disorders, like major depression and Alzheimer's disease. For those reasons, it is prudent to suggest that research efforts should focus on the mechanisms described here, beginning at the level of epigenetics, and projects solely focusing on alterations of the DNA sequence (SNP, CNV etc.) should be considered with caution. For obvious reasons, outcomes of the latter approaches have proved to be disappointing. In general, epidemiological studies are confounded by complex cause and effect relationships, unclear mechanisms by which non-shared environmental factors mediate disease risk, and an inability to reconcile the "heritable" component embedded within what appears to be an environmental domain (Petronis, 2010). First, the temporary or dynamic aspect is completely missing. Second, if some of the genetic variants reached significance levels, the magnitude of the effect of these variants in altering risk, as measured by odds ratios, is generally modest, in the 1.1-2.0 range. One example of such investigations is the meta analysis on the $\mathrm{A} 1166 \mathrm{C}$ variant of the angiotensin II type 1 receptor (AGTR1) and its association to coronary heart disease (CHD), encompassing 53 studies including 20,435 cases and 23,674 controls and covering a total study time of 15 years. The authors produced odds ratio for CHD of 1.10 (95\% CI 1.03-1.19), which completely disappeared when the analysis was restricted to the 11 larger studies with at least 500 cases in each $(O R=0.992,95 \% \mathrm{CI}$ $0.944-1.042)$ or to the 8 studies which were of high quality $(O R=$ 0.990, 95\% CI 0.915-1.072) (Kronenberg and Lamina, 2010). There are also some recent GWAS performed in schizophrenia patients using SNPs to search for single gene defects. The ISC data set included 3322 schizophrenia cases and 3587 controls and approximately 1 million SNPs were analyzed (International Schizophrenia Consortium, 2009). Another data set (SGENE) examined 314,868 SNPs in 2663 schizophrenics and 13,498 controls (Stefansson et al., 2009). In a third data set (MGS), 2681 schizophrenics and 2653 controls were investigated (Shi et al., 2009). It is accepted practice in these types of studies where high quantities of markers and high amounts of samples are included, to adjust for multiple comparisons and set a criterion for type I error at $p<5 \times 10^{-8}$. In these conditions, not even one marker in any of the three separate data sets achieved this level. No significant associations were found (Wahlsten, 2012). Third, once a variant is identified to be statistically associated with a disease, it does not mean that the variant is in fact functionally responsible for altering an individual's disease susceptibility. Fourth, when the effect of multiple risk alleles is estimated using a simple additive model, apparently the combined effect does not explain why these complex disorders have such a strong familial occurrence, a conundrum referred to as the "missing heritability" problem. Fifth, the identification of an association of a gene allele or CNV with a disorder does not permit any clues as to when, how long, at which time, to what extent, in what brain regions the gene product is expressed, and in what molecular or cellular networks it is embedded. In conclusion, the DNA is only the hardware or the blueprint, the rest is self-organization within the limits of the software continuously modified by the environment. In other words, as stated more provocatively by D. Noble: "DNA is not the sole transmitter of inheritance," "There is no genetic program," (a term invented by Jacob and Monod), and "There are no other programs at any other level" (Noble, 2013). In consequence, it is very unlikely that complex mental disorders can be retraced to a set of genes with some sets of specific mutations.

For the great majority of mental illness (admittedly, there are few exceptions) it is well accepted, that they can be characterized as so-called "spectrum disorders," disorders with smooth transitions from discreet to more severe forms or partially overlapping with other disorders. Eventually, each disorder is individually distinct and is dependent on the development of the affected individuals over time, just to repeat the extreme importance of the temporary aspect already mentioned above. For instance, there are reports on relatives of schizophrenic families, who clearly have high similarities of genetic background and showed signs of schizotypy (mild forms with no clinical deficits), but who never came down with diagnosis of schizophrenia (Chapman et al., 1994). These results can be explained by the above said, that despite inherited, "adverse" genetic repertoire, there is sufficient room available to contain these preconditions by favorable environmental conditions.

The accumulated evidence above permits to draw several important conclusions for schizophrenia research: it is trivial to say that gene transcription is distinct in cells of different organs with more or less $50 \%$ of all genes silenced (by epigenetic mechanisms) to encode and maintain cell type specificity. Moreover, in an organ like the brain, transcription in one cell or a group of cells of the same cell type may be different depending on their localization. Well-known examples are the pyramidal neurons of the hippocampus mentioned above. Their communication, that 
is restricted to shorter distances within the high gamma frequencies and contrasts with frequencies in the theta or beta ranges used for long-range communications, supposedly stems from distinct ion channel properties expressed by neurons located in different layers and, hence, in different environments of the hippocampus. Along these lines, schizophrenia has been associated with abnormal amplitude and synchrony of oscillatory activity of neuronal networks, in particular, at high (beta/gamma) frequencies, with evidence for impaired beta/gamma-band oscillations (Uhlhaas and Singer, 2013). Impaired task performance during a perceptual organization task was accompanied by a widespread deficit in the power of gamma-band oscillations between 60 and $120 \mathrm{~Hz}$. Not only the amplitude but also the synchronicity of gamma oscillations was reduced in schizophrenia patients. Accordingly, reduced long-range phase synchronization could lead to a functional disconnection syndrome to eventually constitute a core impairment in schizophrenia. Evidence for an involvement of disturbed beta band oscillations in cognitive deficits in schizophrenia was reported by Ford and Mathalon (2008). Therefore, further research into neural oscillations should also take into account the possibility that the impairments in high frequency oscillations are related to alterations in low-frequency bands, in particular in the theta and alpha frequency ranges, and study more closely the cross-frequency coupling (Figure 1).

But also astrocytes supposedly display differential expression patterns depending on their locations in brain regions, on their cellular contacts (perivascular, perisynaptic, and contact with other glial cell types), in glia-neuronal/glial-glial networks and resulting specific cell-cell interactions. As pointed out above, astrocytes can communicate by expressing receptors or uptake transporters for neurotransmitters, by releasing signaling molecules for neuronal receptors, and by various forms of gap junctions between astrocytes and neurons and only between astrocytes. For instance, in tripartite synapses nonfunctional astrocytic receptors may cause an unconstrained synaptic information flux. Moreover, supposing that in the astrocytic syncytium gap junctions normally form plaques that function as memory devices, loss of function of gap junctions may also cause cognitive impairment (Mitterauer, 2011). The gap junction protein Cx43 is mainly expressed in astrocytes. However, under pathological conditions, it is upregulated in microglia (Eugenín et al., 2001). In both astrocytes and microglia, Cx43 can form functional hemichannels and gap junction channels (Orellana et al., 2011), which play a fundamental role in physiological and pathological processes, and participate in the inflammatory responses of glial cells (Bennett et al., 2012). This introduces an additional crucial system of the body to be considered in terms of learning and memory. There is quite some evidence, that a well-balanced communication between the nervous system and the immune system ensures normal functioning of the organism. Therefore, disturbances in normal function of the immune system lead to impairments in cognition and in neurogenesis (Marin and Kipnis, 2013), which indicates, that engram formation is influenced by the well- or malfunctiong of peripheral systems, as well. Interestingly, increased expression of immune system-associated proteins in brain has been interpreted as indication of ongoing chronic autoimmune processes, which may be true for multiple sclerosis, or for chronic inflammatory processes, like the ones observed in Alzheimer's dementia. However, in the case of schizophrenia there is no compelling evidence of an auto-immune basis. Some studies find upregulated, some others downregulated inflammatory genes. For those somewhat confusing data, the idea has recently been entertained, that the MHC, a gene locus repeatedly identified in GWAS of schizophrenia patients, is not indicative of an immune-related disorder, but may play a role in synaptic plasticity and brain development through nonimmune functions (McGuffin and Power, 2013). Actually, this aspect is not new. Already some years ago, it has been reported, that immunity-associated processes are functionally linked to adaptive neuronal responses, like learning and memory (Havik et al., 2007). Lateron, our microarray study in brains of schizophrenia patients revealed a large number of immunerelated genes, as well, being down-regulated in superior prefrontal cortex (Schmitt et al., 2011). In this report, it has also been emphasized, supported by data accumulated from the literature, that many immune-related genes subserve distinct, but important functions in normal neurotransmission. Consequently, reduced expression of those genes could affect synaptic activities and result in compromised functions of neuronal and glial networks. Therefore, transcription, ensueing translation and PTMs in each cell or cellular compartments, like pre- and postsynaptic sites or astrocytic end feet in contact with neurons or with the vasculature, are permanently subject to processes of adaptation to microand macro-environmental requirements.

These issues are of paramount importance but extremely difficult to pursue on a systems level. The crucial task to pursue is to study the dynamic formation of disease-specific engrams long time before the disorder can be diagnosed. In this context, effects of repetitive mild or medium insults, experimentally inflicted, on engram formation may help to learn more about this crucial encoding of disease provoking molecular processes. To this end, many hands have to be joined to understand the underlying molecular events in more clarity.

\section{SUMMARY AND CONCLUSION}

In summary and conclusion, engram formation appears to begin very early on in life and very likely on several distinct levels of communication, such as on the level of electrical (digital) communication within neuronal networks (bifurcation mode of decision making), possibly as short-term memory, extending on glial networks encompassing primarily analog data processing, and finally on producing imprints (long-term memory) on the molecular levels of DNA (epigenome), RNA (transcriptome), and the proteome. These levels of communication closely interact and steadily reshape their structures like a patchwork of accumulating, countless numbers of engrams that reflect the impact of environmental influences on the organism and, hence, result in dynamic quilt-like patterns specific and unique to each individual. Assemblies of those engrams are supposed to synergize in the development of health or disease, by combinations that are critically dependent on environmental conditions. This view is in stark contrast to the wide-spread deterministic thinking, attributing a major role to genetic variations as cause for the eventual outcome. Admittedly, there are clearly disorders with 
high genetic background (Down's syndrome, cystic fibrosis etc.) but origins of the vast majority of psychiatric disorders will be identified on the highly dynamic levels described here. Therefore, future research should concentrate on identification of diseasespecific (molecular) engrams accumulating over time and their interactions during the latent phases of disease development.

\section{ACKNOWLEDGMENTS}

This work was supported by DAAD/CONICYT International collaboration grants and FONDECYT - Chile \# 1120079; BNI P09-015-F. The author would like to acknowledge the invitation to write this article and the very helpful comments made by Dr. M. Herrera-Marschitz (Chile).

\section{REFERENCES}

Aguado, F., Espinosa-Parrilla, J. F., Carmona, M. A., and Soriano, E. (2002). Neuronal activity regulates correlated network properties of spontaneous calcium transients in astrocytes in situ. J. Neurosci. 22, 9430-9444.

Ahmed, R., Zha, X. M., Green, S. H., and Dailey, M. E. (2006). Synaptic activity and F-actin coordinately regulate CaMKIIalpha localization to dendritic postsynaptic sites in developing hippocampal slices. Mol. Cell. Neurosci. 31, 37-51. doi: 10.1016/j.mcn.2005.08.020

Alberini, C. M. (2009). Transcription factors in long-term memory and synaptic plasticity. Physiol. Rev. 89, 121-145. doi: 10.1152/physrev.00017.2008

Alberini, C. M. (2011). The role of reconsolidation and the dynamic process of long-term memory formation and storage. Front. Behav. Neurosci. 5:12. doi: 10.3389/fnbeh.2011.00012

Alvarez-Maubecin, V., García-Hernández, F., Williams, J. T., and Van Bockstaele, E. J. (2000). Functional coupling between neurons and glia. J. Neurosci. 20, 4091-4098.

Angulo, M. C., Kozlov, A. S., Charpak, S., and Audinat, E. (2004). Glutamate released from glial cells synchronizes neuronal activity in the hippocampus. J. Neurosci. 24, 6920-6927. doi: 10.1523/JNEUROSCI.0473-04.2004

Araque, A., Carmignoto, G., and Haydon, P. G. (2001). Dynamic signalling between astrocytes and neurons. Annu. Rev. Physiol. 63, 795-813. doi: 10.1146/annurev.physiol.63.1.795

Armano, S., Rossi, P., Taglietti, V., and D’Angelo, E. (2000). Long-term potentiation of intrinsic excitability at the mossy fiber-granule cell synapse of rat cerebellum. J. Neurosci. 20, 5208-5216.

Axelsen, L. N., Calloe, K., Holstein-Rathlou, N. H., and Nielsen, M. S. (2013). Managing the complexity of communication: regulation of gap junctions by post-translational modification. Front. Pharmacol. 4:130. doi: 10.3389/fphar.2013.00130

Bank, M., and Schacher, S. (1992). Segregation of presynaptic inputs on an identified target neuron in vitro: structural remodelling visualized over time. J. Neurosci. 12, 2960-2972.

Bailey, C. H., Bartsch, D., and Kandel, E. R. (1989). Toward a molecular definition of long-term memory storage. Proc. Natl. Acad. Sci. U.S.A. 93, 13445-13452. doi: $10.1073 /$ pnas.93.24.13445

Bailey, C. H., Kandel, E. R., and Si, K. (2004). The persistence of long-term memory: a molecular approach to self-sustaining changes in learning-induced synaptic growth. Neuron 44, 49-57. doi: 10.1016/j.neuron.2004.09.017

Bekar, L. K., He, W., and Nedergaard, M. (2008). Locus coeruleus alpha-adrenergicmediated activation of cortical astrocytes in vivo. Cereb. Cortex 18, 2789-2795. doi: 10.1093/cercor/bhn040

Bekar, L. K., and Walz, W. (2002). Intracellular chloride modulates A-type potassium currents in astrocytes. Glia 39, 207-216. doi: 10.1002/glia.10096

Bekkers, J. M. (2000). Distribution and activation of voltage-gated potassium channels in cell-attached and outside-out patches from large layer 5 cortical pyramidal neurons of the rat. J. Physiol. 525, 611-620. doi: 10.1111/j.14697793.2000.t01-2-00611.x

Ben Achour, S., and Pascual, O. (2010). Glia: The many ways to modulate synaptic plasticity. Neurochem. Int. 57, 440-445. doi: 10.1016/j.neuint.2010.02.013

Bennett, M. V., Garre, J. M., Orellana, J. A., Bukauskas, F. F., Nedergaard, M., and Sáez, J. C. (2012). Connexin and pannexin hemichannels in inflammatory responses of glia and neurons. Brain Res. 1487, 3-15. doi: 10.1016/j.brainres.2012.08.042
Bennett, M. V., and Zukin, R. S. (2004). Electrical coupling and neuronal synchronization in the mammalian brain. Neuron 41, 495-511. doi: 10.1016/S08966273(04)00043-1

Benuskova, L., and Kasabov, N. (2007). Modeling L-LTP based on changes in concentration of pCREB transcription factor. Neurocomputing 70, 2035-2040. doi: 10.1016/j.neucom.2006.10.133

Bhaumik, S. R., Smith, E., and Shilatifard, A. (2007). Covalent modifications of histones during development and disease pathogenesis. Nat. Struct. Mol. Biol. 14, 1008-1016. doi: 10.1038/nsmb1337

Bienenstock, E. L., Cooper, L. N., and Munro, P. W. (1982). Theory for the development of neuron selectivity: orientation specificity and binocular interaction in visual cortex. J. Neurosci. 2, 32-48.

Bloodgood, B. L., and Sabatini, B. L. (2007). Ca2+ signaling in dendritic spines. Curr. Opin. Neurobiol. 17, 345-351. doi: 10.1016/j.conb.2007.04.003

Bushong, E. A., Martone, M. E., Jones, Y. Z., and Ellisman, M. H. (2002). Protoplasmic astrocytes in CAl stratum radiatum occupy separate anatomical domains. J. Neurosci. 22, 183-192.

Buzsáki, G., and Chrobak, J. J. (1995). Temporal structure in spatially organized neuronal ensembles: a role for interneuronal networks. Curr. Opin. Neurobiol. 5, 504-510. doi: 10.1016/0959-4388(95)80012-3

Campbell, G., and Shatz, C. J. (1992). Synapses formed by identified retinogeniculate axons during the segregation of eye input. J. Neurosci. 12, 1847-1858.

Canolty, R. T., Edwards, E., Dalal, S. S., Soltani, M., Nagarajan, S. S., Kirsch, H. E., et al. (2006). High gamma power is phase-locked to theta oscillations in human neocortex. Science 313, 1626-1628. doi: 10.1126/science. 1128115

Carpenter, G. A., and Grossberg, S. (1987). A massively parallel architecture for a self-organizing neural pattern recognition machine. Comp. Vis. Graph. Image Proc. 37, 54-115. doi: 10.1016/S0734-189X(87)80014-2

Carracedo, L. M., Kjeldsen, H., Cunnington, L., Jenkins, A., Schofield, I., Cunningham, M. O., et al. (2013). A neocortical delta rhythm facilitates reciprocal interlaminar interactions via nested theta rhythms. J. Neurosci. 33, 10750-10761. doi: 10.1523/JNEUROSCI.0735-13.2013

Chapman, L. J., Chapman, J. P., Kwapil, T. R., Eckblad, M., and Zinser, M. C. (1994). Putatively psychosis-prone subjects 10 years later. J. Abnorm. Psychol. 103, 171-183. doi: 10.1037/0021-843X.103.2.171

Chen, J., Tan, Z., Zeng, L., Zhang, X., He, Y., Gao, W., et al. (2013). Heterosynaptic long-term depression mediated by ATP released from astrocytes. Glia 61, 178-191. doi: 10.1002/glia.22425

Clarke, L. E., and Barres, B. A. (2013). Emerging roles of astrocytes in neural circuit development. Nat. Rev. Neurosci. 14, 311-321. doi: 10.1038/nrn3484

Condorelli, D. F., Parenti, R., Spinella, F., Trovato Salinaro, A., Belluardo, N., Cardile, V., et al. (1998). Cloning of a new gap junction gene (Cx36) highly expressed in mammalian brain neurons. Eur. J. Neurosci. 10, 1202-1208. doi: 10.1046/j.1460-9568.1998.00163.x

Connors, B. W., and Long, M. A. (2004). Electrical synapses in the mammalian brain. Ann. Rev. Neurosci. 27, 393-418. doi: 10.1146/annurev.neuro.26.041002.131128

Costa-Mattioli, M., and Sonenberg, N. (2006). Translational control of long-term synaptic plasticity and memory storage by eIF2alpha. Crit. Rev. Neurobiol. 18, 187-195. doi: 10.1615/CritRevNeurobiol.v18.i1-2.190

Cotrina, M. L., Kang, J., Lin, J. H., Bueno, E., Hansen, T. W., He, L., et al. (1998). Astrocytic gap junctions remain open during ischemic conditions. J. Neurosci. $18,2520-2537$.

Creixell, P., and Linding, R. (2012). Cells, shared memory and breaking the PTM code. Mol. Syst. Biol. 8, 598. doi: 10.1038/msb.2012.33

Dere, E., and Zlomuzica, A. (2012). The role of gap junctions in the brain in health and disease. Neurosci. Biobehav. Rev. 36, 206-217. doi: 10.1016/i.neubiorev.2011.05.015

Dermietzel, R. (1998). Diversification of gap junction proteins (connexins) in the central nervous system and the concept of functional compartments. Cell Biol. Int. 22, 719-730. doi: 10.1006/cbir.1999.0393

Derouiche, A., Anlauf, E., Aumann, G., Muhlstadt, B., and Lavialle, M. (2002). Anatomical aspects of glia-synapse interaction: the perisynaptic glial sheath consists of a specialized astrocyte compartment. J. Physiol. Paris 96, 177-182. doi: 10.1016/S0928-4257(02)00004-9

Dobrowolski, R., and Willecke, K. (2009). Connexin-caused genetic diseases and corresponding mouse models. Antioxid. Redox Signal. 11, 283-295. doi: 10.1089/ars.2008.2128 
Dombeck, D. A., Khabbaz, A. N., Collman, F., Adelman, T. L., and Tank, D. W. (2007). Imaging large-scale neural activity with cellular resolution in awake, mobile mice. Neuron. 56, 43-57. doi: 10.1016/j.neuron.2007.08.003

Dong, Y., Green, T., Saal, D., Marie, H., Neve, R., Nestler, E. J., et al. (2006). CREB modulates excitability of nucleus accumbens neurons. Nat. Neurosci. 9 , 475-477. doi: 10.1038/nn1661

Dudai, Y. (2004). The neurobiology of consolidations, or, how stable is the engram? Annu. Rev. Psychol. 55, 51-86. doi: 10.1146/annurev.psych.55.090902.142050

Eberwine, J., Belt, B., Kacharmina, J. E., and Miyashiro, K. (2002). Analysis of subcellularly localized mRNAs using in situ hybridization, mRNA amplification, and expression profiling. Neurochem. Res. 27, 1065-1077. doi: 10.1023/A:1020956805307

Egawa, K., Yamada, J., Furukawa, T., Yanagawa, Y., and Fukuda, A. (2013). $\mathrm{Cl}$ - homeodynamics in gap junction-coupled astrocytic networks on activation of GABAergic synapses. J. Physiol. 591, 3901-3917. doi: 10.1113/jphysiol.2013.257162

Eichenbaum, H. (2004). Hippocampus: cognitive processes and neural representations that underlie declarative memory. Neuron 44, 109-120. doi: 10.1016/j.neuron.2004.08.028

Escartin, C., and Rouach, N. (2013). Astroglial networking contributes to neurometabolic coupling. Front. Neuroenerg. 5:4. doi: 10.3389/fnene.2013.00004

Eugenín, E. A., Basilio, D., Sáez, J. C., Orellana, J. A., Raine, C. S., Bukauskas, F., et al. (2012). The role of gap junction channels during physiologic and pathologic conditions of the human central nervous system. J. Neuroimmune Pharmacol. 7, 499-518. doi: 10.1007/s11481-012-9352-5

Eugenín, E. A., Eckardt, D., Theis, M., Willecke, K., Bennett, M. V., and Sáez, J. C. (2001). Microglia at brain stab wounds express connexin 43 and in vitro form functional gap junctions after treatment with interferon-gamma and tumor necrosis factor-alpha. Proc. Natl. Acad. Sci. U.S.A. 98, 4190-4195. doi: 10.1073/pnas.051634298

Feldman, D. E. (2002). Synapses, scaling and homeostasis in vivo. Nat. Neurosci. 5, 712-714. doi: 10.1038/nn0802-712

Fellin, T., Pascual, O., Gobbo, S., Pozzan, T., Haydon, P. G., and Carmignoto, G. (2004). Neuronal synchrony mediated by astrocytic glutamate through activation of extrasynaptic NMDA receptors. Neuron 43, 729-743. doi: 10.1016/j.neuron.2004.08.011

Fiacco, T. A., and McCarthy, K. D. (2004). Intracellular astrocyte calcium waves in situ increase the frequency of spontaneous AMPA receptor currents in CA1 pyramidal neurons. J. Neurosci. 24, 722-732. doi: 10.1523/JNEUROSCI.285903.2004

Fields, D. R., and Stevens-Graham, B. (2002). New insights into neuron-glia communication. Science 298, 556-562. doi: 10.1126/science.298.5593.556

Fields, R. D., Araque, A., Johansen-Berg, H., Lim, S. S., Lynch, G., Nave, K. A., et al. (2014). Glial biology in learning and cognition. Neuroscientist. doi: 10.1177/ 1073858413504465. [Epub ahead of print].

Finnie, P. S., and Nader, K. (2012). The role of metaplasticity mechanisms in regulating memory destabilization and reconsolidation. Neurosci. Biobehav. Rev. 36, 1667-1707. doi: 10.1016/j.neubiorev.2012.03.008

Ford, J. M., and Mathalon, D. H. (2008). Neural synchrony in schizophrenia. Schizophr. Bull. 34, 904-906. doi: 10.1093/schbul/sbn090

Foss, J., Longtin, A., Mensour, B., and Milton, J. (1996). Multistability and delayed recurrent loops. Phys. Rev. Lett. 76, 708-711. doi: 10.1103/PhysRevLett.76.708

Fregnac, Y. (1998). Homeostasis or synaptic plasticity? Nature 391, 845-846. doi: $10.1038 / 35996$

Frey, U., and Morris, R. G. (1997). Synaptic tagging and longterm potentiation. Nature 385, 533-536. doi: 10.1038/385533a0

Frisch, C., De Souza-Silva, M. A., Söhl, G., Güldenagel, M., Willecke, K., Huston, J. P., et al. (2005). Stimulus complexity dependent memory impairment and changes in motor performance after deletion of the neuronal gap junction protein connexin 36 in mice. Behav. Brain Res. 157, 177-185. doi: 10.1016/j.bbr.2004.06.023

Fukuda, T. (2007). Structural organization of the gap junction network in the cerebral cortex. Neuroscientist 13, 199-207. doi: 10.1177/1073858406296760

Fukuda, T., Kosaka, T., Singer, W., and Galuske, R. A. (2006). Gap junctions among dendrites of cortical GABAergic neurons establish a dense and widespread intercolumnar network. J. Neurosci. 26, 3434-3443. doi: 10.1523/JNEUROSCI.407605.2006

Fuster, J. M., and Alexander, G. E. (1971). Neuron activity related to short-term memory. Science 173, 652-654. doi: 10.1126/science.173.3997.652
Giaume, C., Koulakoff, A., Roux, L., Holcman, D., and Rouach, N. (2010). Astroglial networks: a step further in neuroglial and gliovascular interactions. Nat. Rev. Neurosci. 11, 87-99. doi: 10.1038/nrn2757

Giaume, C., and McCarthy, K. D. (1996). Control of gap-junctional communication in astrocytic networks. Trends Neurosci. 19, 319-325. doi: 10.1016/01662236(96)10046-1

Gordon, G. R. J., Iremonger, K. J., Kantevari, S., Ellis-Davies, G. C. R., MacVicar, B. A., and Bains, J. S. (2009). Astrocyte-mediated distributed plasticity at hypothalamic glutamate synapses. Neuron 64, 391-403. doi: 10.1016/j.neuron.2009.10.021

Govindarajan, A., Kelleher, R. J., and Tonegawa, S. (2006). A clustered plasticity model of long-term memory engrams. Nat. Rev. Neurosci. 7, 575-583. doi: $10.1038 / \mathrm{nrn} 1937$

Graber, T. E., Hébert-Seropian, S., Khoutorsky, A., David, A., Yewdell, J. W., Lacaille, J. C., et al. (2013b). Reactivation of stalled polyribosomes in synaptic plasticity. Proc. Natl. Acad. Sci. U.S.A. 110, 16205-16210. doi: 10.1073/pnas.1307747110

Graber, T. E., McCamphill, P. K., and Sossin, W. S. (2013a). A recollection of mTOR signaling in learning and memory. Learn. Mem. 20, 518-530. doi: 10.1101/lm.027664.112

Gray, N. W., Weimer, R. M., Bureau, I., and Svoboda, K. (2006). Rapid redistribution of synaptic PSD-95 in the neocortex in vivo. PLoS Biol. 4:e370. doi: 10.1371/journal.pbio.0040370

Gupta, S., Kim, S. Y., Artis, S., Molfese, D. L., Schumacher, A., Sweatt, J. D., et al. (2010). Histone methylation regulates memory formation. J. Neurosci. 30, 3589-3599. doi: 10.1523/JNEUROSCI.3732-09.2010

Gupta-Agarwal, S., Franklin, A. V., Deramus, T., Wheelock, M., Davis, R. L., McMahon, L. L., et al. (2012). G9a/GLP histone lysine dimethyltransferase complex activity in the hippocampus and the entorhinal cortex is required for gene activation and silencing during memory consolidation. J. Neurosci. 32, 5440-5453. doi: 10.1523/JNEUROSCI.0147-12.2012

Guzowski, J. F., McNaughton, B. L., Barnes, C. A., and Worley, P. F. (1999) Environment-specific expression of the immediate-early gene Arc in hippocampal neuronal ensembles. Nat. Neurosci. 2, 1120-1124. doi: 10.1038/16046

Haber, M., Zhou, L., and Murai, K. K. (2006). Cooperative astrocyte and dendritic spine dynamics at hippocampal excitatory synapses. J. Neurosci. 26, 8881-8891. doi: 10.1523/JNEUROSCI.1302-06.2006

Hama, H., Hara, C., Yamaguchi, K., and Miyawaki, A. (2004). PKC signalling mediates global enhancement of excitatory synaptogenesis in neurons triggered by local contact with astrocytes. Neuron 41, 405-415. doi: 10.1016/S08966273(04)00007-8

Han, X., Chen, M., Wang, F., Windrem, M., Wang, S., Shanz, S., et al. (2013). Forebrain engraftment by human glial progenitor cells enhances synaptic plasticity and learning in adult mice. Cell Stem Cell 12, 342-353. doi: 10.1016/j.stem.2012.12.015

Hart, G. W., Housley, M. P., and Slawson, C. (2007). Cycling of O-linked beta-Nacetylglucosamine on nucleocytoplasmic proteins. Nature 446, 1017-1022. doi: 10.1038/nature05815

Havik, B., Rokke, H., Dagyte, G., Stavrum, A. K., Bramham, C. R., and Steen, V. M. (2007). Synaptic activity-induced global gene expression patterns in the dentate gyrus of adult behaving rats: induction of immunity-linked genes. Neuroscience 148, 925-936. doi: 10.1016/j.neuroscience.2007.07.024

Henneberger, C., Papouin, T., Oliet, S. H., and Rusakov, D. A. (2010). Longterm potentiation depends on release of D-serine from astrocytes. Nature 463 , 232-236. doi: 10.1038/nature08673

Hinton, G. E., Osindero, S. 0, and Tej, Y. H. (2006). A fast learning algorithm for deep belief nets. Neural Comput. 18, 1527-1554. doi: 10.1162/neco.2006.18.7.1527

Hoffman, D. A., Magee, J. C., Colbert, C. M., and Johnston, D. (1997). K+ channel regulation of signal propagation in dendrites of hippocampal pyramidal neurons. Nature 387, 869-875. doi: 10.1038/42571

Hoogland, T. M., Kuhn, B., Göbel, W., Huang, W., Nakai, J., Helmchen, F., et al. (2009). Radially expanding transglial calcium waves in the intact cerebellum. Proc. Natl. Acad. Sci. U.S.A. 106, 3496-3501. doi: 10.1073/pnas.0809 269106

Hormuzdi, S. G., Filippov, M. A., Mitropoulou, G., Monyer, H., and Bruzzone, R. (2004). Electrical synapses: a dynamic signaling system that shapes the activity of neuronal networks. Biochem. Biophys. Acta 1662, 113-137. doi: 10.1016/j.bbamem.2003.10.023 
Houades, V., Koulakoff, A., Ezan, P., Seif, I., and Giaume, C. (2008). Gap junctionmediated astrocytic networks in the mouse barrel cortex. J. Neurosci. 28, 5207-5217. doi: 10.1523/JNEUROSCI.5100-07.2008

Hunter, T. (2007). The age of crosstalk: phosphorylation, ubiquitination, and beyond. Mol. Cell 28, 730-738. doi: 10.1016/j.molcel.2007.11.019

International Schizophrenia Consortium. (2009). Common polygenic variation contributes to risk of schizophrenia and bipolar disorder. Nature 460, 748-752. doi: $10.1038 /$ nature 08185

Jarome, T. J., Werner, C. T., Kwapis, J. L., and Helmstetter, F. J. (2011). Activity dependent protein degradation is critical for the formation and stability of fear memory in the amygdale. PLoS ONE 6:e24349. doi: 10.1371/journal.pone.0024349

Jarome, T. J., and Lubin, F. D. (2013). Histone lysine methylation: critical regulator of memory and behavior. Rev. Neurosci. 24, 375-387. doi: 10.1515/revneuro2013-0008

Johnston, D., and Narayanan, R. (2008). Active dendrites: colorful wings of the mysterious butterflies. Trends Neurosci. 31, 309-316. doi: 10.1016/j.tins.2008.03.004

Jourdain, P., Bergersen, L. H., Bhaukaurally, K., Bezzi, P., Santello, M., Domercq, M., et al. (2007). Glutamate exocytosis from astrocytes controls synaptic strength. Nat. Neurosci. 10, 331-339. doi: 10.1038/nn1849

Kang, J., Kang, N., Lovatt, D., Torres, A., Zhao, Z., Lin, J., et al. (2008). Connexin 43 hemichannels are permeable to ATP. J. Neurosci. 28, 4702-4711. doi: 10.1523/JNEUROSCI.5048-07.2008

Kavalali, E. T., Zhuo, M., Bito, H., and Tsien, R. W. (1997). Dendritic Ca2+ channels characterized by recordings from isolated hippocampal dendritic segments. Neuron 18, 651-663. doi: 10.1016/S0896-6273(00)80305-0

Kelleher, R. J. 3rd, Govindarajan, A., and Tonegawa, S. (2004). Translational regulatory mechanisms in persistent forms of synaptic plasticity. Neuron 44, 59-73. doi: 10.1016/j.neuron.2004.09.013

Kelly, M. T., Crary, J. F., and Sacktor, T. C. (2007). Regulation of protein kinase Mzeta synthesis by multiple kinases in long-term potentiation. J. Neurosci. 27, 3439-3444. doi: 10.1523/JNEUROSCI.5612-06.2007

Kim, S. J., and Linden, D. J. (2007). Ubiquitous plasticity and memory storage. Neuron 56, 582-592. doi: 10.1016/j.neuron.2007.10.030

Klann, E., and Sweatt, J. D. (2008). Altered protein synthesis is a trigger for long-term memory formation. Neurobiol. Learn. Mem. 89, 247-259. doi: 10.1016/j.nlm.2007.08.009

Koch, H., Garcia A. J. 3rd., and Ramirez, J. M. (2011). Network reconfiguration and neuronal plasticity in rhythm-generating networks. Integr. Comp. Biol. 51, 856-868. doi: 10.1093/icb/icr099

Kole, M. H., Hallermann, S., and Stuart, G. J. (2006). Single Ih channels in pyramidal neuron dendrites: properties, distribution, and impact on action potential output. J. Neurosci. 26, 1677-1687. doi: 10.1523/JNEUROSCI.3664-05.2006

Koulakoff, A., Ezan, P., and Giaume, C. (2008). Neurons control the expression of connexin30 and connexin 43 in mouse cortical astrocytes. Glia 56, 1299-1311. doi: 10.1002/glia.20698

Kreuzberg, M. M., Deuchars, J., Weiss, E., Schober, A., Sonntag, S., Wellershaus, K., et al. (2008). Expression of connexin30.2 in interneurons of the central nervous system in the mouse. Mol. Cel. Neurosci. 37, 119-134. doi: 10.1016/j.mcn.2007.09.003

Kronenberg, F., and Lamina, C. (2010). The evaporation of positive genetic association findings. When time has come to go. Atherosclerosis 213, 30-32. doi: 10.1016/j.atherosclerosis.2010.07.049

Kunze, A., Congreso, M. R., Hartmann, C., Wallraff-Beck, A., Huttmann, K., Bedner, P., et al. (2009). Connexin expression by radial glia-like cells is required for neurogenesis in the adult dentate gyrus. Proc. Natl. Acad. Sci. U.S.A. 106, 11336-11341. doi: 10.1073/pnas.0813160106

Kwapis, J. L., and Helmstetter, F. J. (2013). Does PKM(zeta) maintain memory? Brain Res. Bull. doi: 10.1016/j.brainresbull.2013.09.005. [Epub ahead of print].

Lampe, P. D. (1994). Analyzing phorbol ester effects on gap junctional communication: a dramatic inhibition of assembly. J. Cell Biol. 127, 1895-1905. doi: 10.1083/jcb.127.6.1895

Lang, C., Barco, A., Zablow, L., Kandel, E. R., Siegelbaum, S. A., and Zakharenko, S. S. (2004). Transient expansion of synaptically connected dendritic spines upon induction of hippocampal long-term potentiation. Proc. Natl. Acad. Sci. U.S.A. 101, 16665-16670. doi: 10.1073/pnas.0407581101

Latham, J. A., and Dent, S. Y. (2007). Cross-regulation of histone modifications. Nat. Struct. Mol. Biol. 14, 1017-1024. doi: 10.1038/nsmb1307
Law, J. A., and Jacobsen, S. E. (2010). Establishing, maintaining and modifying DNA methylation patterns in plants and animals. Nat. Rev. Genet. 11, 204-220. doi: $10.1038 / \operatorname{nrg} 2719$

Lee, A. K., Manns, I. D., Sakmann, B., and Brecht, M. (2006). Whole-cell recordings in freely moving rats. Neuron 51, 399-407. doi: 10.1016/j.neuron.2006. 07.004

Lee, J. L. (2010). Memory reconsolidation mediates the updating of hippocampal memory content. Front. Behav. Neurosci. 4:168. doi: 10.3389/fnbeh.2010. 00168

Letzkus, J. J., Kampa, B. M., and Stuart, G. J. (2006). Learning rules for spike timing-dependent plasticity depend on dendritic synapse location. J. Neurosci. 26, 10420-10429. doi: 10.1523/JNEUROSCI.2650-06.2006

Liao, L., Pilotte, J., Xu, T., Wong, C. C., Edelman, G. M., Vanderklish, P., et al. (2007). BDNF induces widespread changes in synaptic protein content and up-regulates components of the translation machinery: an analysis using highthroughput proteomics. J. Proteome Res. 6, 1059-1071. doi: 10.1021/pr060358f

Lichtman, J. W., Livet, J., and Sanes, J. R. (2008). A technicolour approach to the connectome. Nat. Rev. Neurosci. 9, 417-422. doi: 10.1038/nrn2391

Lim, W. A. (2002). The modular logic of signaling proteins: building allosteric switches from simple binding domains. Curr. Opin. Struct. Biol. 12, 61-88. doi: 10.1016/S0959-440X(02)00290-7

Lim, W. A., and Pawson, T. (2010). Phosphotyrosine signaling: evolving a new cellular communication system. Cell 142, 661-667. doi: 10.1016/j.cell.2010.08.023

Lim, S., and Goldman, M. S. (2013). Balanced cortical microcircuitry for maintaining information in working memory. Nat. Neurosci. 16, 1306-1314. doi: 10.1038/nn.3492

Lisman, J., and Raghavachari, S. (2006). A unified model of the presynaptic and postsynaptic changes during LTP at CA1 synapses. Sci. STKE 2006:re11. doi: 10.1126/stke.3562006re11

Liu, X., Ramirez, S., Pang, P. T., Puryear, C. B., Govindarajan, A., Deisseroth, K., et al. (2012). Optogenetic stimulation of a hippocampal engram activates fear memory recall. Nature 484, 381-385. doi: 10.1038/nature11028

London, M., and Häusser, M. (2005). Dendritic computation. Annu. Rev. Neurosci. 28, 503-532. doi: 10.1146/annurev.neuro.28.061604.135703

Loo, L. W., Berestecky, J. M., Kanemitsu, M. Y., and Lau, A. F. (1995). pp60srcmediated phosphorylation of connexin 43, a gap junction protein. J. Biol. Chem. 270, 12751-12761. doi: 10.1074/jbc.270.21.12751

Lopez, F., Jobe, T. H., and Helgason, C. (2006). A fuzzy theory of cortical computation: Neuropoietic engrams, fuzzy hypercubes, and the nature of consciousness. Med. Hypotheses 66, 121-132. doi: 10.1016/j.mehy.2005.07.015

Lörincz, A., Notomi, T., Tamás, G., Shigemoto, R., and Nusser, Z. (2002). Polarized and compartment-dependent distribution of $\mathrm{HCN} 1$ in pyramidal cell dendrites. Nat. Neurosci. 5, 1185-1193. doi: 10.1038/nn962

Losonczy, A., and Magee, J. C. (2006). Integrative properties of radial oblique dendrites in hippocampal CA1 pyramidal neurons. Neuron 50, 291-307. doi: 10.1016/j.neuron.2006.03.016

Losonczy, A., Makara, J. K., and Magee, J. C. (2008). Compartmentalized dendritic plasticity and input feature storage in neurons. Nature 452, 436-441. doi: 10.1038 /nature06725

Madison, D. V., Malenka, R. C., and Nicoll, R. A. (1986). Phorbol esters block a voltage-sensitive chloride current in hippocampal pyramidal cells. Nature 321, 695-697. doi: 10.1038/321695a0

Marin, I., and Kipnis, J. (2013). Learning and memory... and the immune system. Learn. Mem. 20, 601-606. doi: 10.1101/lm.028357.112

Markram, H., Helm, P. J., and Sakmann, B. (1995). Dendritic calcium transients evoked by single back-propagating action potentials in rat neocortical pyramidal neurons. J. Physiol. 485, 1-20.

Martin, K. C., and Zukin, R. S. (2006). RNA trafficking and local protein synthesis in dendrites: an overview. J. Neurosci. 26, 7131-7134. doi: 10.1523/JNEUROSCI.1801-06.2006

Matsumoto, M., Setou, M., and Inokuchi, K. (2007). Transcriptome analysis reveals the population of dendritic RNAs and their redistribution by neural activity. Neurosci. Res. 57, 411-423. doi: 10.1016/j.neures.2006.11.015

Matus, A., Brinkhaus, H., and Wagner, U. (2000). Actin dynamics in dendritic spines: a form of regulated plasticity at excitatory synapses. Hippocampus. 10, 555-560. doi: 10.1002/1098-1063(2000) 10:5<555::AID-HIPO5>3.0.CO;2-Z

McGuffin, P., and Power, R. A. (2013). Schizophrenia as a human leukocyte antigen-associated disease revisited. Am. J. Psychiatry 170, 821-823. doi: 10.1176/appi.ajp.2013.13030336 
McNaughton, B. L., Barnes, C. A., and Andersen, P. (1981). Synaptic efficacy and EPSP summation in granule cells of rat fascia dentata studied in vitro. J. Neurophysiol. 46, 952-966.

Meier, S. D., Kafitz, K. W., and Rose, C. R. (2008). Developmental profile and mechanisms of GABA-induced calcium signaling in hippocampal astrocytes. Glia 56, 1127-1137. doi: 10.1002/glia.20684

Melchor, J. P., and Strickland, S. (2005). Tissue plasminogen activator in central nervous system physiology and pathology. Thromb. Haemost. 93, 655-660. doi: 10.1160/TH04-12-0838

Meme, W., Vandecasteele, M., Giaume, C., and Venance, L. (2009). Electrical coupling between hippocampal astrocytes in rat brain slices. Neurosci. Res. 63, 236-243. doi: 10.1016/j.neures.2008.12.008

Miller, C. A., and Sweatt, J. D. (2007). Covalent modification of DNA regulates memory formation. Neuron 53, 857-869. doi: 10.1016/j.neuron.2007.02.022

Minguez, P., Parca, L., Diella, F., Mende, D. R., Kumar, R., Helmer-Citterich, M., et al. (2012). Deciphering a global network of functionally associated posttranslational modifications. Mol. Sys. Biol. 8, 599. doi: 10.1038/msb.2012.31

Minguez, P., Letunic, I., Parca, L., and Bork, P. (2013). PTMcode: a database of known and predicted functional associations between post-translational modifications in proteins. Nucl. Ac. Res. 41, D306-D311. doi: 10.1093/nar/gks1230

Mitterauer, B. J. (2011). Possible role of glia in cognitive impairment in schizophrenia. CNS Neurosci. Ther. 17, 333-344. doi: 10.1111/j.1755-5949.2009.00113.x

Mozzachiodi, R., and Byrne, J. H. (2010). More than synaptic plasticity: role of nonsynaptic plasticity in learning and memory. Trends Neurosci. 33, 17. doi: 10.1016/j.tins.2009.10.001

Murai, K. K., Nguyen, L. N., Irie, F., Yamaguchi, Y., and Pasquale, E. B. (2003). Control of hippocampal dendritic spine morphology through ephrinA3/EphA4 signaling. Nat. Neurosci. 6, 153-160. doi: 10.1038/nn994

Nagy, J. I., Lynn, B. D., Tress, O., Willecke, K., and Rash, J. E. (2011). Connexin26 expression in brain parenchymal cells demonstrated by targeted connexin ablation in transgenic mice. Eur. J. Neurosci. 34, 263-271. doi: 10.1111/j.14609568.2011.07741.x

Nagy, J. I., and Rash, J. E. (2000). Connexins and gap junctions of astrocytes and oligodendrocytes in the CNS. Brain Res. Brain Res. Rev. 32, 29-44. doi: 10.1016/S0165-0173(99)00066-1

Narayanan, R., and Johnston, D. (2007). Long-term potentiation in rat hippocampal neurons is accompanied by spatially widespread changes in intrinsic oscillatory dynamics and excitability. Neuron 56, 1061-1075. doi: 10.1016/j.neuron.2007.10.033

Nedergaard, M., Ransom, B., and Goldman, S. A. (2003). New roles for astrocytes: redefining the functional architecture of the brain. Trends Neurosci. 26, 523-530. doi: 10.1016/j.tins.2003.08.008

Nett, W. J., Oloff, S. H., and McCarthy, K. D. (2002). Hippocampal astrocytes in situ exhibit calcium oscillations that occur independent of neuronal activity. J. Neurophysiol. 87, 528-537.

Noble, D. (2013). The MUSIC of LIFE (OUP), Biology Beyond the Genome. Chapter 4. A Sourcebook. Version 4. Available online at: http://musicoflife.co.uk/pdfs/ The\%20Music\%20of\%20Life-sourcebook.pdf (Accessed September, 2013).

Oberheim, N. A., Wang, X., Goldman, S., and Nedergaard, M. (2006). Astrocytic complexity distinguishes the human brain. Trends Neurosci. 29, 547-553. doi: 10.1016/j.tins.2006.08.004

Orellana, J. A., Shoji, K. F., Abudara, V., Ezan, P., Amigou, E., Sáez, P. J., et al. (2011). Amyloid beta-induced death in neurons involves glial and neuronal hemichannels. J. Neurosci. 31, 4962-4977 doi: 10.1523/JNEUROSCI.6417-10.2011

Orosz, G., Ashwin, P., and Townley, S. (2009). Learning of spatio-temporal codes in a coupled oscillator system. IEEE Trans. Neural Netw. 20, 1135-1147. doi: 10.1109/TNN.2009.2016658

Pajevic, S., Basser, P. J., and Fields, R. D. (2013). Role of myelin plasticity in oscillations and synchrony of neuronal activity. Neuroscience. doi: 10.1016/ j.neuroscience.2013.11.007. [Epub ahead of print].

Panatier, A., Vallée, J., Haber, M., Murai, K. K., Lacaille, J. C., and Robitaille, R. (2011). Astrocytes are endogenous regulators of basal transmission at central synapses. Cell 146, 785-798. doi: 10.1016/j.cell.2011.07.022

Pannasch, U., Derangeon, M., Chever, O., and Rouach, N. (2012). Astroglial gap junctions shape neuronal network activity. Commun. Integr. Biol. 5, 248-254. doi: $10.4161 /$ cib. 19410

Pannasch, U., Vargova, L., Reingruber, J., Ezan, P., Holcman, D., Giaume, C., et al. (2011). Astroglial networks scale synaptic activity and plasticity. Proc. Natl. Acad. Sci. U.S.A. 108, 8467-8472. doi: 10.1073/pnas.1016650108
Pape, H. C. (1996). Queer current and pacemaker: the hyperpolarizationactivated cation current in neurons. Annu. Rev. Physiol. 58, 299-327. doi: 10.1146/annurev.ph.58.030196.001503

Parpura, V., Basarsky, T. A., Liu, F., Jeftinija, K., Jeftinija, S., and Haydon, P. G. (1994). Glutamate-mediated astrocyte-neuron signalling. Nature 369, 744-747. doi: 10.1038/369744a0

Pastalkova, E., Serrano, P., Pinkhasova, D., Wallace, E., Fenton, A. A., and Sacktor, T. C. (2006). Storage of spatial information by the maintenance mechanism of LTP. Science 313, 1141-1144. doi: 10.1126/science.1128657

Pellerin, L., Bouzier-Sore, A. K., Aubert, A., Serres, S., Merle, M., Costalat, R., et al. (2007). Activity-dependent regulation of energy metabolism by astrocytes: an update. Glia 55, 1251-1262. doi: 10.1002/glia.20528

Pellerin, L., and Magistretti, P. J. (2012). Sweet sixteen for ANLS. J. Cereb. Blood Flow Metab. 32, 1152-1166. doi: 10.1038/jcbfm.2011.149

Perea, G., and Araque, A. (2005). Properties of synaptically evoked astrocyte calcium signal reveal synaptic information processing by astrocytes. J. Neurosci. 25, 2192-2203. doi: 10.1523/JNEUROSCI.3965-04.2005

Perea, G., and Araque, A. (2006). Synaptic information processing by astrocytes. J. Physiol.-Paris 99, 92-97. doi: 10.1016/j.jphysparis.2005.12.003

Perea, G., and Araque, A. (2007). Astrocytes potentiate transmitter release at single hippocampal synapses. Science 317, 1083-1086. doi: 10.1126/science.1144640

Perkel, D. H. (1988). Logical neurons: the enigmatic legacy of Warren McCulloch. Trends Neurosci. 11, 9-12. doi: 10.1016/0166-2236(88)90041-0

Petronis, A. (2010). Epigenetics as a unifying principle in the aetiology of complex traits and diseases. Nature 465, 721-727. doi: 10.1038/nature09230

Phelan, P., Goulding, L. A., Tam, J. L., Allen, M. J., Dawber, R. J., Davies, J. A., et al. (2008). Molecular mechanism of rectification at identified electrical synapses in the Drosophila giant fiber system. Curr. Biol. 18, 1955-1960. doi: 10.1016/j.cub.2008.10.067

Pouget, A., Beck, J. M., Ma, W. J., and Latham, P. E. (2013). Probabilistic brains: knowns and unknowns. Nat. Neurosci. 16, 1170-1178. doi: 10.1038/nn.3495

Ramirez, J. M., Tryba, A. K., and Pena, F. (2004). Pacemaker neurons and neuronal networks: an integrative view. Curr. Opin. Neurobiol. 14, 665-674. doi: 10.1016/j.conb.2004.10.011

Redondo, R. L., and Morris, R. G. (2011). Making memories last: the synaptic tagging and capture hypothesis. Nat. Rev. Neurosci. 12, 17-30. doi: $10.1038 / \mathrm{nrn} 2963$

Redondo, R. L., Okuno, H., Spooner, P. A., Frenguelli, B. G., Bito, H., and Morris, R. G. (2010). Synaptic tagging and capture: differential role of distinct calcium/calmodulin kinases in protein synthesis-dependent long-term potentiation. J. Neurosci. 30, 4981-4989. doi: 10.1523/JNEUROSCI.314009.2010

Ren, S. Q., Yan, J. Z., Zhang, X. Y., Bu, Y. F., Pan, W. W., Yao, W., et al. (2013). PKC lambda is critical in AMPA receptor phosphorylation and synaptic incorporation during LTP. EMBO J. 32, 1365-1380. doi: 10.1038/emboj. 2013.60

Retamal, M. A., Cortes, C. J., Reuss, L., Bennett, M. V., and Saez, J. C. (2006) $S$-nitrosylation and permeation through connexin43 hemichannels in astrocytes:induction by oxidant stress and reversal by reducing agents. Proc. Natl. Acad. Sci. U.S.A. 103, 4475-4480. doi: 10.1073/pnas.0511118103

Retamal, M. A., Yin, S., Altenberg, G. A., and Reuss, L. (2009). Modulation of Cx46 hemichannels by nitric oxide. Am. J. Physiol. Cell Physiol. 296, C1356-C1363. doi: 10.1152/ajpcell.00054.2009

Rottingen, J. A., and Iversen, J. G. (2000). Ruled by waves? Intracellular and intercellular calcium signalling. Acta Physiol. Scand. 169, 203-219. doi: 10.1046/j.1365201x.2000.00732.x

Rouach, N., Koulakoff, A., Abudara, V., Willecke, K., and Giaume, C. (2008). Astroglial metabolic networks sustain hippocampal synaptic transmission. Science 322, 1551-1555. doi: 10.1126/science. 1164022

Routtenberg, A. (1972). Memory as input-output reciprocity: an integrative neurobiological theory. Ann. N.Y. Acad. Sci. 193, 159-174. doi: 10.1111/j.1749 6632.1972.tb27832.x

Routtenberg, A. (2008a). Long-lasting memory from evanescent networks. Eur. J. Pharmacol. 585, 60-63. doi: 10.1016/j.ejphar.2008.02.047

Routtenberg, A. (2008b). The substrate for long-lasting memory: if not protein synthesis, then what? Neurobiol. Learn. Mem. 89, 225-233. doi: 10.1016/j.nlm.2007.10.012

Routtenberg, A. (2013). Lifetime memories from persistently supple synapses. Hippocampus 23, 202-206. doi: 10.1002/hipo.22088 
Routtenberg, A., and Rekart, J. L. (2005). Post-translational protein modification as the substrate for long-lasting memory. Trends Neurosci. 28, 12-19. doi: 10.1016/j.tins.2004.11.006

Ruthenburg, A. J., Li, H., Patel, D. J., and Allis, C. D. (2007). Multivalent engagement of chromatin modifications by linked binding modules. Nat. Rev. Mol. Cell Biol. 8, 983-994. doi: 10.1038/nrm2298

Saar, D., and Barkai, E. (2003). Long-term modifications in intrinsic neuronal properties and rule learning in rats. Eur. J. Neurosci. 17, 2727-2734. doi: 10.1046/j.1460-9568.2003.02699.x

Sáez, J. C., Contreras, J. E., Bukauskas, F. F., Retamal, M. A., and Bennett, M. V. (2003). Gap junction hemichannels in astrocytes of the CNS. Acta Physiol. Scand. 179, 9e22. doi: 10.1046/j.1365-201X.2003.01196.x

Sakaguchi, M., and Hayashi, Y. (2012). Catching the engram: strategies to examine the memory trace. Mol. Brain 5, 32. doi: 10.1186/1756-6606-5-32

Salameh, A., and Dhein, S. (2005). Pharmacology of gap junctions. New pharmacological targets for treatment of arrhythmia, seizure and cancer? Biochem Biophys. Acta 1719, 36-58. doi: 10.1016/j.bbamem.2005.09.007

Sanabria, H., Swulius, M. T., Kolodziej, S. J., Liu, J., and Waxham, M. N. (2009). \{beta\}CaMKII regulates actin assembly and structure. J. Biol. Chem. 284, 9770-9780. doi: 10.1074/jbc.M809518200

Schafer, D. P., Lehrman, E. K., and Stevens, B. (2013). The "quad-partite" synapse: microglia-synapse interactions in the developing and mature CNS. Glia 61, 24-36. doi: 10.1002/glia.22389

Schmitt, A., Leonardi-Essmann, F., Durrenberger, P. F., Parlapani, E., SchneiderAxmann, T., Spanagel, R., et al. (2011). Regulation of immune-modulatory genes in left superior temporal cortex of schizophrenia patients: a genome-wide microarray study. World J. Biol. Psychiatry 12, 201-215. doi: $10.3109 / 15622975.2010 .530690$

Seet, B. T., Dikic, I., Zhou, M., and Pawson, T. (2006). Reading protein modifications with interaction domains. Nat. Rev. Mol. Cell. Biol. 7, 473-483. doi: $10.1038 / \mathrm{nrm} 1960$

Seibt, J., and Frank, M. G. (2012). Translation regulation in sleep: making experience last. Commun. Integr. Biol. 5, 491-495. doi: 10.4161/cib.21010

Semon, R. (1921). The Mneme. London: G. Allen and Unwin ltd.

Shelton, M. K., and McCarthy, K. D. (2000). Hippocampal astrocytes exhibit $\mathrm{Ca} 2+$-elevating muscarinic cholinergic and histaminergic receptors in situ. J. Neurochem. 74, 555-563. doi: 10.1046/j.1471-4159.2000.740555.x

Shema, R., Haramati, S., Ron, S., Hazvi, S., Chen, A., Sacktor, T. C., et al. (2011). Enhancement of consolidated long-term memory by overexpression of protein kinase Mzeta in the neocortex. Science 331, 1207-1210. doi: 10.1126/science. 1200215

Shi, J., Levinson, D. F., Duan, J., Sanders, A. R., Zheng, Y., Pe'er, I., et al. (2009). Common variants on chromosome $6 \mathrm{p} 22.1$ are associated with schizophrenia. Nature 460, 753-757. doi: 10.1038/nature08192

Siegel. M., Donner, T. H., and Engel, A. K. (2012). Spectral fingerprints of large-scale neuronal interactions. Nat. Rev. Neurosci. 13, 121-134. doi: $10.1038 / \mathrm{nrn} 3137$

Slezak, M., Pfrieger, F. W., and Soltys, Z. (2006). Synaptic plasticity, astrocytes and morphological homeostasis. J. Physiol.-Paris 99, 84-91. doi: 10.1016/j.jphysparis.2005.12.082

Sonenberg, N., and Dever, T. E. (2003). Eukaryotic translation initiation factors and regulators. Curr. Opin. Struct. Biol. 13, 56-63. doi: 10.1016/S0959440X(03)00009-5

Spencer, W. A., and Kandel, E. R. (1961). Electrophysiology of hippocampal neurons. IV. Fast prepotentials. J. Neurophysiol. 24, 272-285.

Squire, L. R. (2009). Memory and brain systems: 1969-2009. J. Neurosci. 29, 12711-12716. doi: 10.1523/JNEUROSCI.3575-09.2009

Squire, L. R., Stark, C. E., and Clark, R. E. (2004). The medial temporal lobe. Annu. Rev. Neurosci. 27, 279-306. doi: 10.1146/annurev.neuro.27.070203.144130

Stefansson, H., Ophoff, R. A., Steinberg, S., Andreassen, O. A., Cichon, S., Rujescu, D., et al. (2009). Common variants conferring risk of schizophrenia. Nature 460 , 744-747. doi: 10.1038/nature08186

Stehberg, J., Moraga-Amaro, R., Salazar, C., Becerra, A., Echeverria, C., Orellana, J. A., et al. (2012). Release of gliotransmitters through astroglial connexin 43 hemichannels is necessary for fear memory consolidation in the basolateral amygdala. FASEB J. 26, 3649-3657. doi: 10.1096/fj.11-198416

Steward, O., and Levy, W. B. (1982). Preferential localization of polyribosomes under the base of dendritic spines in granule cells of the dentate gyrus. J. Neurosci. 2, 284-291.
Stuart, G. J., and Sakmann, B. (1994). Active propagation of somatic action potentials into neocortical pyramidal cell dendrites. Nature 367, 69-72. doi: 10.1038/367069a0

Sui, L., Wang, Y., Ju, L. H., and Chen, M. (2012). Epigenetic regulation of reelin and brain-derived neurotrophic factor genes in long-term potentiation in rat medial prefrontal cortex. Neurobiol. Learn. Mem. 97, 425-440. doi: 10.1016/j.nlm.2012.03.007

Sutherland, R. J., and Lehmann, H. (2011). Alternative conceptions of memory consolidation and the role of the hippocampus at the systems level in rodents. Curr. Opin. Neurobiol. 21, 446-451. doi: 10.1016/j.conb.2011.04.007

Suzuki, A., Stern, S. A., Bozdagi, O., Huntley, G. W., Walker, R. H., Magistretti, P. J., et al. (2011). Astrocyte-neuron lactate transport is required for long-term memory formation. Cell 144, 810-823. doi: 10.1016/j.cell.2011.02.018

Tanaka, M., Shih, P. Y., Gomi, H., Yoshida, T., Nakai, J., Ando, R., et al. (2013). Astrocytic $\mathrm{Ca} 2+$ signals are required for the functional integrity of tripartite synapses. Mol. Brain 6, 6. doi: 10.1186/1756-6606-6-6

Taverna, S. D., Ueberheide, B. M., Liu, Y., Tackett, A. J., Diaz, R. L., Shabanowitz J., et al. (2007). Longdistance combinatorial linkage between methylation and acetylation on histone H3 N termini. Proc. Natl. Acad. Sci. U.S.A. 104, 2086-2091. doi: 10.1073/pnas.0610993104

Theiss, C., and Meller, K. (2002). Microinjected anti-actin antibodies decrease gap junctional intercellular communication in cultured astrocytes. Exp. Cell Res. 281, 197-204. doi: 10.1006/excr.2002.5652

Todd, K. J., Serrano, A., Lacaille, J. C., and Robitaille, R. (2006). Glial cells in synaptic plasticity. J. Physiol.-Paris 99, 75-83. doi: 10.1016/j.jphysparis.2005 12.002

Tress, O., Maglione, M., May, D., Pivneva, T., Richter, N., Seyfarth, J., et al. (2012). Panglial gap junctional communication is essential for maintenance of myelin in the CNS. J. Neurosci. 32, 7499-7518. doi: 10.1523/JNEUROSCI.039212.2012

Tretter, F., and Gebicke-Haerter, P. J. (2012). "Systems biology in psychiatric research: from complex data sets over wiring diagrams to computer simulations," in Psychiatric Disorders: Methods and Protocols, Methods in Molecular Biology, Vol. 829. Chapter 36. (Berlin: Springer Science+Business Media), 567-592. LLC 2012. doi: 10.1007/978-1-61779-458-2 36

Tretter, F., Gebicke-Haerter, P. J., Mendoza, E. R., and Winterer, G. (2010). Systems Biology in Psychiatric Research. From High-Throughput Data to Mathematical Modelling. Weinheim: Wiley-Blackwell. doi: 10.1002/9783527630271

Triesch, J. (2007). Synergies between intrinsic and synaptic plasticity mechanisms. Neural Comput. 19, 885-909. doi: 10.1162/neco.2007.19.4.885

Tsuriel, S., Geva, R., Zamorano, P., Dresbach, T., Boeckers, T., Gundelfinger, E. D., et al. (2006). Local sharing as a predominant determinant of synaptic matrix molecular dynamics. PLoS Biol. 4:e271. doi: 10.1371/journal.pbio.0040271

Uhlhaas, P. J., and Singer, W. (2013). High-frequency oscillations and the neurobiology of schizophrenia. Dialogues Clin. Neurosci. 15, 301-313.

Ullian, E. M., Sapperstein, S. K., Christopherson, K. S., and Barres, B. A. (2001) Control of synapse number by glia. Science 291, 657-661. doi: 10.1126/science.291.5504.657

Vandecasteele, M., Glowinski, J., and Venance, L. (2006). Connexin mRNA expression in single dopaminergic neurons of substantia nigra pars compacta Neurosci. Res. 56, 419-426. doi: 10.1016/j.neures.2006.08.013

Vazdarjanova, A., and Guzowski, J. F. (2004). Differences in hippocampal neuronal population responses to modifications of an environmental context: evidence for distinct, yet complementary, functions of CA3 and CA1 ensembles. J. Neurosci. 24, 6489-6496. doi: 10.1523/JNEUROSCI.0350-04.2004

Venance, L., Glowinski, J., and Giaume, C. (2004). Electrical and chemical transmission between striatal GABAergic output neurones in rat brain slices. J. Physiol. 559, 215-230. doi: 10.1113/jphysiol.2004.065672

Ventriglia, F. (2008). The engram formation and the global oscillations of CA3. Cogn. Neurodyn. 2, 335-345. doi: 10.1007/s11571-008-9057-x

Vinogradova, O. S. (2001). Hippocampus as comparator: role of the two input and two output systems of the hippocampus in selection and registration of information. Hippocampus 11, 578-598. doi: 10.1002/hipo.1073

von Stein, A., and Sarnthein, J. (2000). Different frequencies for different scales of cortical integration: from local gamma to long range alpha/theta synchronization. Int. J. Psychophysiol. 38, 301-313. doi: 10.1016/S0167-8760(00)00172-0

Wade, J. J., McDaid, L. J., Santos, J. A., and Sayers, H. M. (2010). SWAT: a spiking neural network training algorithm for classification problems. IEEE Trans. Neurol Netw. 21, 1817-1830. doi: 10.1109/TNN.2010.2074212 
Wahlsten, D. (2012). The hunt for gene effects pertinent to behavioral traits and psychiatric disorders: from mouse to human. Dev. Psychobiol. 54, 475-492. doi: 10.1002/dev.21043

Wallace, J. G., and Bluff, K. (1995). “Should ANN be ANGN?," in From Natural to Artificial Neural Computation. Lecture Notes in Computer Science, Vol. 930, eds J. Mira and F. Sandoval (Berlin: Springer), 53-60.

Wang, H., Hu, Y., and Tsien, J. Z. (2006). Molecular and systems mechanisms of memory consolidation and storage. Prog. Neurobiol. 79, 123-135. doi: 10.1016/j.pneurobio.2006.06.004

Warn-Cramer, B. J., Cottrell, G. T., Burt, J. M., and Lau, A. F. (1998). Regulation of connexin43 gap junctional intercellular communication by mitogenactivated protein kinase. J. Biol. Chem. 273, 9188-9196. doi: 10.1074/jbc.273. 15.9188

Wasseff, S. K., and Scherer, S. S. (2011). Cx32 and Cx47 mediate oligodendrocyte:astrocyte and oligodendrocyte:oligodendrocyte gap junction coupling. Neurobiol. Dis. 42, 506-513. doi: 10.1016/j.nbd.2011.03.003

Watts, D. J., and Strogatz, S. H. (1998). Collective dynamics of "small-world" networks. Nature 393, 440-442. doi: 10.1038/30918

Weeber, E. J., Beffert, U., Jones, C., Christian, J. M., Forster, E., Sweatt, J. D., et al. (2002). Reelin and ApoE receptors cooperate to enhance hippocampal synaptic plasticity and learning. J. Biol. Chem. 277, 39944-39952. doi: 10.1074/jbc.M205147200

Willecke, K., Eiberger, J., Degen, J., Eckardt, D., Romualdi, A., Guldenagel, M., et al. (2002). Structural and functional diversity of connexin genes in the mouse and human genome. Biol. Chem. 383, 725-737. doi: 10.1515/BC.2002.076

Wiltgen, B. J., Brown, R. A., Talton, L. E., and Silva, A. J. (2004). New circuits for old memories: the role of the neocortex in consolidation. Neuron 44, 101-108. doi: 10.1016/j.neuron.2004.09.015

Wittenberg, G. M., and Tsien, J. Z. (2002). An emerging molecular and cellular framework for memory processing by the hippocampus. Trends Neurosci. 25, 501-505. doi: 10.1016/S0166-2236(02)02231-2

Xu, J., Kang, N., Jiang, L., Nedergaard, M., and Kang, J. (2005). Activity-dependent long-term potentiation of intrinsic excitability in hippocampal CA1 pyramidal neurons. J. Neurosci. 25, 1750-1760. doi: 10.1523/JNEUROSCI.4217-04.2005
Yamamoto, T., Vukelic, J., Hertzberg, E. L., and Nagy, J. I. (1992). Differential anatomical and cellular patterns of connexin43 expression during postnatal development of rat brain. Brain Res. Dev. Brain Res. 66, 165-180. doi: 10.1016/0165-3806(92)90077-A

Yang, X. D., Korn, H., and Faber, D. S. (1990). Long-term potentiation of electrotonic coupling at mixed synapses. Nature 348, 542-545. doi: 10.1038/348542a0

Yao, Y., Kelly, M. T., Sajikumar, S., Serrano, P., Tian, D., Bergold, P. J., et al. (2008). PKM zeta maintains late long-term potentiation by N-ethylmaleimidesensitive factor/GluR2-dependent trafficking of postsynaptic AMPA receptors. J. Neurosci. 28, 7820-7827. doi: 10.1523/JNEUROSCI.0223-08.2008

Yuste, R., and Urban, R. (2004). Dendritic spines and linear networks. J. Physiol. Paris 98, 479-486. doi: 10.1016/j.jphysparis.2005.09.014

Zou, S., Chen, Y., Ma, J., and Wu, J. (2012). Delay for the capacity-simplicity dilemma in associative memory attractor networks. Neurol Netw. 29-30, 37-51. doi: 10.1016/j.neunet.2012.01.007

Zovkic, I. B., Guzman-Karlsson, M. C., and Sweatt, J. D. (2013). Epigenetic regulation of memory formation and maintenance. Learn. Mem. 20, 61-74. doi: $10.1101 / \mathrm{lm} .026575 .112$

Conflict of Interest Statement: The author declares that the research was conducted in the absence of any commercial or financial relationships that could be construed as a potential conflict of interest.

Received: 29 November 2013; accepted: 02 May 2014; published online: 28 May 2014. Citation: Gebicke-Haerter PJ (2014) Engram formation in psychiatric disorders. Front. Neurosci. 8:118. doi: 10.3389/fnins.2014.00118

This article was submitted to Systems Biology, a section of the journal Frontiers in Neuroscience.

Copyright (c) 2014 Gebicke-Haerter. This is an open-access article distributed under the terms of the Creative Commons Attribution License (CC BY). The use, distribution or reproduction in other forums is permitted, provided the original author(s) or licensor are credited and that the original publication in this journal is cited, in accordance with accepted academic practice. No use, distribution or reproduction is permitted which does not comply with these terms. 